\title{
Towards a druggable epitranscriptome: Compounds that target RNA modifications in cancer
}

\author{
María Berdasco $^{1,2}$ (1) | Manel Esteller ${ }^{3,4,5,6}$ @
}

${ }^{1}$ Epigenetic Therapies Group, Experimental and Clinical Hematology Program (PHEC), Josep Carreras Leukaemia Research Institute, Barcelona, Spain

${ }^{2}$ Cancer Epigenetics and Biology Program (PEBC), Bellvitge Biomedical Research Institute (IDIBELL), Barcelona, Spain

${ }^{3}$ Cancer Epigenetics Group, Cancer and Leukemia Epigenetics and Biology Program (PEBCL), Josep Carreras Leukaemia Research Institute (IJC), Barcelona, Spain

${ }^{4}$ Centro de Investigación Biomédica en Red Cáncer (CIBERONC), Madrid, Spain

${ }^{5}$ Physiological Sciences Department, School of Medicine and Health Sciences, University of Barcelona, Barcelona, Spain

${ }^{6}$ Institució Catalana de Recerca i Estudis Avançats (ICREA), Barcelona, Spain

\section{Correspondence}

María Berdasco, Epigenetic Therapies Group, Experimental and Clinical Hematology Program (PHEC), Josep Carreras Leukaemia Research Institute, Badalona, Barcelona, Catalonia, Spain.

Email:mberdasco@carrerasresearch.org

Manel Esteller, Cancer Epigenetics Group, Cancer and Leukemia Epigenetics and Biology Program (PEBCL), Josep Carreras Leukaemia Research Institute (IJC), Badalona, Barcelona, Catalonia, Spain.

Email: mesteller@carrerasresearch.org

Funding information

Ministerio de Ciencia e Innovacion (MCI), Grant/Award Number: RTI2018-094049-B-I00
Epitranscriptomics is an exciting emerging area that studies biochemical modifications of RNA. The field has been opened up by the technical efforts of the last decade to characterize and quantify RNA modifications, and this has led to a map of post-transcriptional RNA marks in normal cell fate and development. However, the scientific interest has been fuelled by the discovery of aberrant epitranscriptomes associated with human diseases, mainly cancer. The challenge is now to see whether epitrancriptomics offers mechanisms that can be effectively targeted by low MW compounds and are thus druggable. In this review, we will describe the principal RNA modifications (with a focus on mRNA), summarize the latest scientific evidence of their dysregulation in cancer and provide an overview of the state-of-the-art drug discovery to target the epitranscriptome. Finally, we will discuss the principal challenges in the field of chemical biology and drug development to increase the potential of targeted-RNA for clinical benefit.

\section{KEYWORDS}

A-to-I-editing, cancer, epitranscriptomics, pseudouridine, RNA methylation, small-molecule inhibitors, therapy

Abbreviations: AML, acute myeloid leukaemia; A-to-l, adenosine-to-inosine; CDS, coding regions; CML, chronic myeloid leukaemia; CTCL, cutaneous T-cell lymphoma; DNMT, DNA methyltransferases; EMT, epithelial-mesenchymal transition; ESCC, oesophageal squamous cell carcinoma; GBM, glioblastoma multiforme; HCC, hepatocellular carcinoma; HDAC, histone deacetylases; hm5C, 5-hydroxymethyl cytidine; HMT, histone methyltransferases; HNSCC, head and neck squamous carcinoma; KMT, lysine protein methyltransferases; m1A, N1-methyladenosine; m5C, 5-methyl cytidine; m6A, N6-methyladenosine; MA2, ethyl ester of meclofenamic acid; MDS, myelodysplastic syndrome; miRNA, microRNA ncRNA, non-coding RNA; MM, multiple myeloma; NSCLC, non-small cell lung cancer; PDX, patient-derived xenograft; PTCL, peripheral T-cell lymphoma; rRNA, ribosomal RNA; SAM, S-adenosylmethionine; UTR, untranslated regions; $\Psi$, pseudouridine.

This is an open access article under the terms of the Creative Commons Attribution-NonCommercial-NoDerivs License, which permits use and distribution in any medium, provided the original work is properly cited, the use is non-commercial and no modifications or adaptations are made.

(c) 2021 The Authors. British Journal of Pharmacology published by John Wiley \& Sons Ltd on behalf of British Pharmacological Society. 


\section{1 | INTRODUCTION}

The control of chromatin structure mediated by epigenetic mechanisms has an accepted role in the control of gene expression and other DNA-related biological processes. DNA methylation/ demethylation and post-translational modifications of histones set an epigenetic landscape that is stable during cell replication and that could be modulated by specific environmental signals to guide normal development and cell differentiation (Allis \& Jenuwein, 2016; Dai et al., 2020). This orchestrated setting is also subject to deviations. Epigenetic alterations are associated with not only multiple human disorders, including de novo epimutations (e.g. cancer, neurological disorders, infectious diseases or cardiovascular pathologies), but also germline-related diseases (e.g. rare disorders associated with genetic mutations affecting epigenetic modifiers) (Berdasco \& Esteller, 2019). Our knowledge of epigenetic alterations in disease has improved the discovery and development of low MW compounds targeting the catalytic pocket of enzymes with epigenetic activity (Ganesan et al., 2019; Jones et al., 2019). Such epigenetic proteins include enzymes that add chemical groups into DNA and histones (writers), proteins that remove these chemical tags (erasers) and specific binding domain proteins that are able to identify and interpret these modifications (readers) (Ganesan, 2018; Ganesan et al., 2019). DNA methyltransferase (DNMT) inhibitors such as decitabine have been translated into clinical practice for the treatment of haematological malignancies, such as myelodysplastic syndromes (MDS), acute myeloid leukaemia (AML) and chronic myeloid leukaemia (CML) (Diesch et al., 2016; Prebet et al., 2014). Similarly, histone deacetylase (HDAC) inhibitors, such as panobinostat, have also received FDA approval for clinical use in refractory CML (Cavenagh \& Popat, 2018). New approaches in epidrug development explore the presence of genetic mutations of epigenome-modifying enzymes as a more targeted therapy (Cossío et al., 2020). Thus, the histone methyltransferase (HMT) EZH2 inhibitor tazemetostat reached a Phase II/III clinical trial to treat refractory non-Hodgkin lymphoma with EZH2 amplification (Italiano et al., 2018) or the DOT1L inhibitor pinometostat for the treatment of MLL-fusion leukaemia (Stein et al., 2018). Opportunities have extended beyond cancer and the potential of epigenetic drugs as therapeutic agents able to reverse epigenetic defects is extending to other pathologies, ranging from infectious diseases to brain diseases, cardiovascular and metabolic disorders (Ballestar \& Li, 2017; Berdasco \& Esteller, 2019; Villanueva et al., 2020). The volume of epigenetic research conducted in academia, the R\&D sector of pharmaceutical industry and biotech companies have greatly increased the epigenetic-based market.

Following the epigenetic model, recent discoveries on the role of post-translational modifications at the RNA level (termed 'epitranscriptome') have opened new possibilities for the pharmacological targeting of these modifications as an intervention strategy in human diseases with aberrant epitranscriptomes. Over the last 50 years, more than 140 posttranslational modifications in RNA molecules have been identified (Boccaletto et al., 2018), most of them affecting the most abundant RNAs: ribosomal RNA (rRNA) and transfer RNA (tRNA; Roundtree, Evans, et al., 2017). However, it is only during the past decade that we have started to construct the first maps of mRNA modifications and to envision their effects on gene regulation.

The four RNA bases (A, T, C and U) as well as the ribose sugar can harbour modification sites that range from base isomerization processes to chemical modifications, including inosine (I), 5-methylcytidine (m5C; also known as $5 \mathrm{mC})$, 5-hydroxylmethylcytidine ( $\mathrm{hm} 5 \mathrm{C}$; also known as $5 \mathrm{hmC}$ ), pseudo-uridine $(\Psi)$, N6-methyladenosine (m6A) and N1-methyladenosine (m1A). At present, we have identified and characterized mRNA posttranslational modifications that are known to be important for RNA biogenesis, RNA dynamism and RNA function under physiological conditions. In addition, their effects on the onset and progression of human diseases, especially cancer, have been recently examined. Despite all efforts, the field of epitranscriptomics is still in its infancy, and we are still far from obtaining a complete landscape of RNA modifications and the molecular and biological pathways in which they are involved. What is clear from the latest evidence, however, is that RNA does not merely act as an effector molecule, but it has an active role in the regulation of gene expression. In this review, we will describe the principal RNA modifications (with a focus on mRNA), summarize the latest scientific evidences of their dysregulation in cancer and provide an overview of the state-of-the-art drug discovery efforts. Finally, we will discuss the principal challenges in the field of chemical biology and drug development to increase the potential of targetedRNA for clinical benefit.

\section{2 | THE EPITRANSCRIPTOME VERSUS THE EPIGENOME}

Today, a lot rests on whether the novel field of epitranscriptomics will follow the exploitation plan reached by epigenetics in drug development. To perform a critical overview, we need to identify common and divergent features between epigenetic and epitranscriptome modifications. Both RNA and DNA modifications share common features, including their reversibility and dynamics determined by a set of proteins with writer, reader or eraser function, and how these proteins react to changing external conditions (Dominissini et al., 2016; Fu et al., 2014; Roundtree \& He, 2016). Regrettably, we still do not have a full picture of the extent of RNA modifications and the associated enzymic machinery, but a general overview is possible. So far, the number of RNA modifications is high, and they involve a considerable number of writers, erasers and readers. These enzymes are potential pharmacological targets, generating efforts to modify their catalytic activity or their target binding sites. In addition, RNA modifications, such as epigenetic modifications, have been established in a cell type and timedependent manner.

Major differences include the following aspects: (i) in contrast with the primary role of DNA modifications as regulators of gene 
transcription, all type of RNA modifications can be associated with wider aspects of gene expression, including splicing, distribution, translation and stability. The function seems to be strongly dependent on the specification of the type of RNA involved. The same RNA modification can be recognized by multiple readers in a contextdependent manner, resulting in different mechanisms of action and affecting various biological pathways (Jia et al., 2011; Wang et al., 2014). (ii) RNAs demonstrate mobility between cellular compartments, a characteristic that amplifies their effects on multiple biological pathways. (iii) Their heritability: although epigenetic modifications show mitotic inheritance, so far, a transmission of RNA modifications have not been described. When RNA degradation occurs, the epitranscriptomic mark is lost. (iv) The structural effect: although DNA methylation does not alter the double helix DNA structure, RNA modifications could result in altered charge, base-pairing potential, secondary structure, and protein-RNA interactions (Liu et al., 2015). This conformational change also influences how the modification works functionally, because changes in RNA modifications could be read not only directly by their targets but also indirectly though the effect on their structural change.

Altogether, we can assume that the 'RNA world' is extremely complex and the current level of knowledge is still somewhat limited.
In the following sections, we will introduce the major research pathways to making RNA-modifications a realistic target in drug discovery.

\section{3 | NON-CANONICAL CODING RNA MODIFICATIONS: DISTRIBUTION, DYNAMICS AND FUNCTION}

\section{1 | N6-methyladenosine}

N6-methyladenosine (m6A) is the most abundant internal modification detected in mammalian mRNAs $(0.2 \%-0.6 \%$ of all adenosines) (Śledź \& Jinek, 2016). Its abundance together with the development of robust detection methods created an intense research interest, and nowadays, m6A is the best characterized RNA modification. It consists of the addition of a methyl group at the nitrogen- 6 position of adenosine (Figure 1). The methyltransferase-like 3 (METTL3)-METTL14 heterodimer is involved in the methylation process, where METTL3 is the catalytic subunit and METTL14 acts as the RNA-binding scaffold for substrate recognition (Śledź \& Jinek, 2016). Another m6A writer protein is METTL16, a U6 snRNA m6A methyltransferase. METTL16

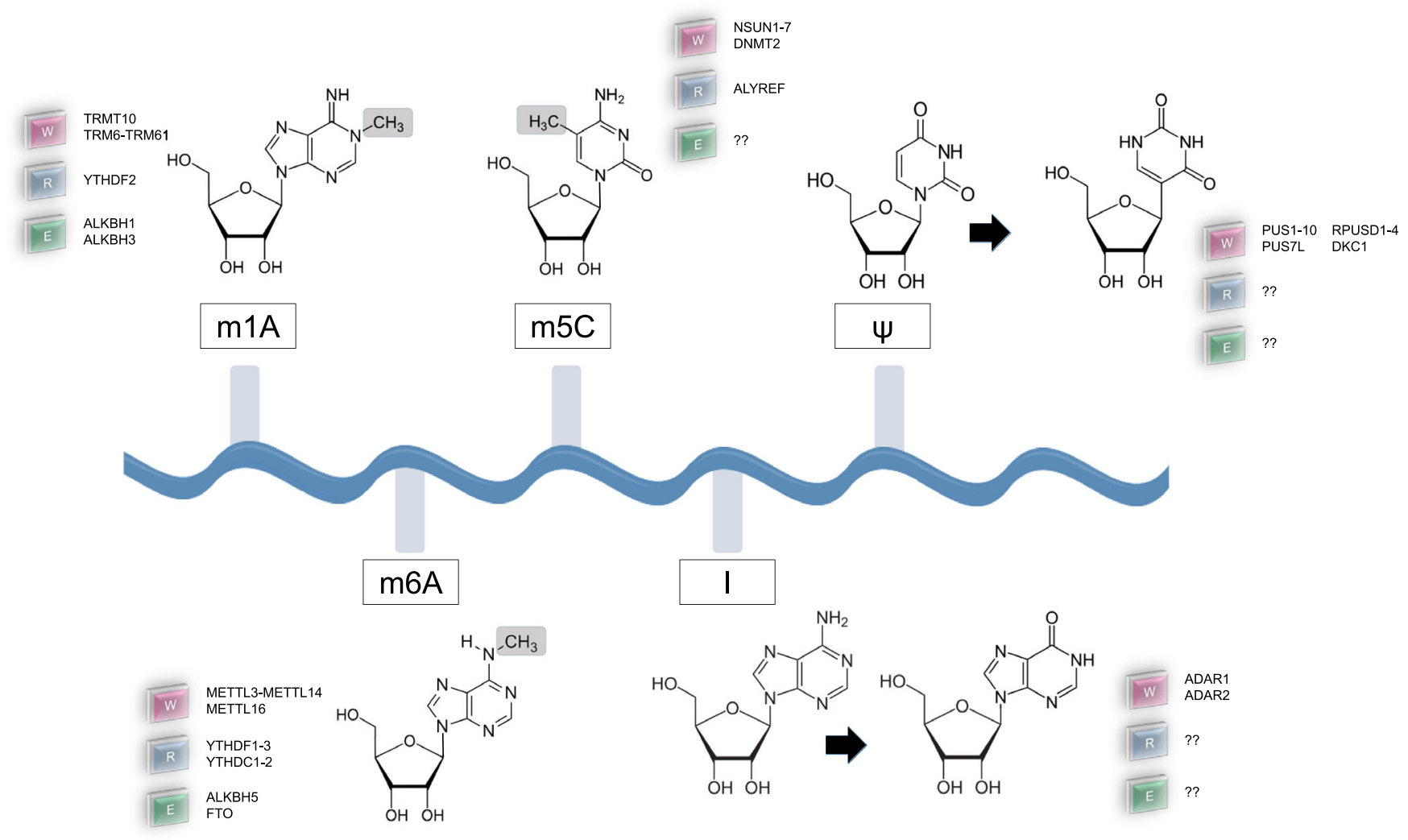

FIGURE 1 Schematic diagram of the predominant mRNA covalent modifications. Reactions for methylation at nucleosides, pseudouridylation and adenosine-to-inosine editing are illustrated. The known writers $(W)$, erasers $(E)$ and readers $(R)$ for each RNA modification are listed together with the modification. $\Psi$, pseudouridine; I, adenosine-to-inosine edition; m1A, N1-methyladenosine; m5C, 5-methyl cytidine; m6A, N6-methyladenosine 
is involved in the regulation of the cellular levels of S-adenosylmethionine (SAM), the methyl donor for methylation, as well as in the mRNA splicing process (Pendleton et al., 2017). Apart from passive $\mathrm{m} 6 \mathrm{~A}$ demethylation of the transcriptome, this modification is actively removed by the action of the fat mass and obesityassociated protein (FTO) (Jia et al., 2011) and AlkB homologue 5 (ALKBH5) (Zheng et al., 2013) demethylases. FTO and ALKBH5 proteins are dioxygenases known to demethylate $\mathrm{N}$-methylated nucleic acids. $\mathrm{m} 6 \mathrm{~A}$ readers have been also identified, included m6A-binding proteins belonging to the YTH family (YTHDF and YTHDC proteins) (Xiao et al., 2016), IGF2BP proteins (Huang et al., 2018), and some heterogeneous nuclear ribonucleoproteins (hnRNP) (Alarcón, Goodarzi, et al., 2015).

Generally, m6A deposition in mRNA occurs in a sequencedependent manner, mainly in the coding regions (CDS) and $3^{\prime}$ untranslated regions (UTR) with a significant enrichment just upstream of the stop codon (Dominissini et al., 2012; Meyer et al., 2012). Interestingly, trimethylation of histone H3 at Lys36 (H3K36me3) has been shown to influence m6A deposition into specific genomic sequences by recruiting the METTL14 complex (Huang, Weng, et al., 2019). Chromatin immunoprecipitation (ChIP)sequencing studies demonstrated that approximately $70 \%$ of $\mathrm{m} 6 \mathrm{~A}$ peaks overlapped with H3K36me3 sites (Huang, Weng, et al., 2019). Altogether, the association between histone $\mathrm{H} 3 \mathrm{~K} 36 \mathrm{me} 3$ and m6A RNA methylation adds a new layer of complexity in the control of gene expression. Further research focused on such integration of epigenetic and epitranscriptomic signals to explain gene control is likely in the near future.

The wide range of readers could explain why m6A is involved in almost of aspects of post-transcriptional gene regulation and mRNA life cycle, including mRNA stability, splicing and translation. For instance, the m6A readers YTHDF1 and YTHDF2 control mRNA stability during stem cell differentiation and modulates processes such as haematopoietic stem and progenitor cell specification (Li, Qian, et al., 2018; Zhang, Chen, Sun, et al., 2017), neural induction from induced pluripotency stem cells (Heck et al., 2020), mammalian spermatogenesis (Hsu et al., 2017) or circadian regulation of downstream genes involved in lipid metabolism (Zhong et al., 2018). By recognizing m6A on pre-mRNA, YTHDC1, hnRNPC, hnRNPG and hnRNPA2B1 could also modulate mRNA splicing (Alarcón, Goodarzi, et al., 2015 Liu et al., 2015; Xiao et al., 2016). YTHDC1 could also mediate nuclear export of processed RNAs into cytoplasm (Roundtree, Luo, et al., 2017). In addition to regulating RNA stability and splicing, m6A reader proteins, including YTHDF1, YTHDF3, IGF2BP1/2/3 and YTHDC2, supervise the RNA translation process and RNA decay (Huang et al., 2018; Shi et al., 2017). Strikingly, the deposition of m6A in $3^{\prime}$ UTRs suggest that $\mathrm{m} 6 \mathrm{~A}$ could be incorporated into specific miRNA target sequences to modulate miRNA-binding (Alarcón, Lee, et al., 2015). And vice versa, microRNAs were shown to regulate m6A modification via a sequence pairing mechanism and to affect cell reprogramming in pluripotency (Chen et al., 2015). This finding reinforces the importance of the crosstalk between the epigenome and epitranscriptome in the control of gene regulation.

\section{2 | N1-methyladenosine}

The N1-methyladenosine modification ( $\mathrm{m} 1 \mathrm{~A})$, or the addition of a methyl group at the nitrogen-1 position of adenosine (Figure 1), was described decades ago to primarily affect all classes of RNAs (Barbieri \& Kouzarides, 2020). It is predominant in tRNA and rRNA, but it was recently shown in mRNA (Boccaletto et al., 2018). So far, there is very little information of its frequency, the key players involved in $\mathrm{m} 1 \mathrm{~A}$ regulation and its consequences in mRNA. Although its frequency in cytosolic mRNA is controversial, it is accepted that m1A is about 10 times less abundant than m6A (Dominissini et al., 2016; Safra et al., 2017). The m1A modification maps uniquely to GC-rich, $5^{\prime}$-UTR positions in coding transcripts (Safra et al., 2017). An aspect of interest is that, unlike m6A, m1A occurs in the Watson-Crick interface carrying a positively charged base at this position (Roundtree, Evans, et al., 2017). Alterations to protein-RNA interactions and RNA secondary/tertiary structures could be expected. The effects of the $\mathrm{m} 1 \mathrm{~A}$ modification are still being elucidated and some recent results suggest a role in the initiation of mRNA translation (Dominissini et al., 2016; $\mathrm{Li}$, Xiong, et al., 2016) by facilitating non-canonical binding of the exon-exon junction complex at $5^{\prime}$-UTRs, devoid of $5^{\prime}$ proximal introns (Cenik et al., 2017). Its relevance to the control of regulation is supported by its high conservation in mouse and human cells (Cenik et al., 2017).

The only known m1A writer of cytosolic mRNA is the TRM6-TRM61 complex and its activity also produces $\mathrm{m} 1 \mathrm{~A}$ in the mitochondrial-encoded transcripts (Li, Xiong, et al., 2017; Safra et al., 2017). The m1A modification can be removed from mRNA by ALKBH3, a m1A demethylase, acting on both mRNA and tRNA (Dominissini et al., 2016; Esteve-Puig et al., 2020; Li, Huang, et al., 2016). The YTH protein family of $\mathrm{m} 6 \mathrm{~A}$ readers could also interpret m1A signals. Specifically, YTHDF1-3 and YTHDC1 bound directly to m1A in mRNA in human cancer cells (Dai et al., 2018). New insights into the functions of m1A in RNA biology are needed as, so far, only a role in the response to various types of cellular stress has been proposed (Dominissini et al., 2016; Li, Xiong, et al., 2016).

\section{3 | 5-methylcytosine}

Like DNA, all types of RNA molecules can be methylated at carbon 5 of cytosine giving rise to 5 -methylcytosine ( $\mathrm{m} 5 \mathrm{C}$ ) (Figure 1), yielding diverse functions depending on the type of RNA (Trixl \& Lusser, 2019). The abundance of $\mathrm{m} 5 \mathrm{C}$ in mRNA is under strong debate and discrepancies come from the technical difficulties to establish the transcriptome-mapping of $\mathrm{m} 5 \mathrm{C}$, mainly due to incomplete conversion of cytidine and $\mathrm{m} 5 \mathrm{C}$ during bisulfite treatment. It is estimated that about $62 \%-70 \%$ of cytosine sites had low methylation levels $(<20 \%$ methylation), whereas $8 \%-10 \%$ of the sites were moderately or highly methylated (>40\% methylation) (Huang, Chen, et al., 2019). The location of $\mathrm{m} 5 \mathrm{C}$ modifications primarily maps to CDS, although an enrichment has been also observed in the $5^{\prime}$-UTR and the $3^{\prime}$-UTR regions (Huang, Chen, et al., 2019). 
The writers of RNA m5C modifications in mammals include seven members of the NOL1/NOP2/SUN domain family member (NSUN) family (NSUN1-7), and DNA methyltransferase-like 2 (DNMT2). However, so far only NSUN2 has been shown to methylate mRNA (Yang, Yang, et al., 2017). In this regard, only overexpression/ suppression of NSUN2 but not of any other NSUN enzyme, affected overall m5C levels in mRNA from HeLa cells (Yang, Yang, et al., 2017). Regrettably, enzymes that remove $5 \mathrm{mC}$ from RNA species have not yet been identified.

As we are only beginning to uncover the biology of $\mathrm{m} 5 \mathrm{C}$ in mRNA, not much is known about the potential functional consequences. A role for $\mathrm{m} 5 \mathrm{C}$ in the regulation of nuclear export has been discovered (Yang, Yang, et al., 2017). Specifically, the activity of the nuclear export factor ALYREF/THOC4 is strongly affected by the $\mathrm{m} 5 \mathrm{C}$ level of its target mRNAs (Yang, Yang, et al., 2017). The $5 \mathrm{mC}$ deposition is not a random event because $5 \mathrm{mC}$ accumulates at translational start codon and in a CG sequence context. In addition, $\mathrm{m} 5 \mathrm{C}$ can act as a modulator of protein translation. Examples include the $\mathrm{m} 5 \mathrm{C}$ accumulation at $5^{\prime}$-UTR of cyclin-dependent kinase inhibitor ${ }^{\mathrm{p} 27} \mathrm{KIP} 1$ during replicative senescence (Tang et al., 2015), or $\mathrm{m} 5 \mathrm{C}$ deposition in the $3^{\prime}$-UTRs of the cell cycle regulators CDK1 and p21 during the cell division cycle (Xing et al., 2015).

Physiologically, NSUN2 is involved in many biological pathways. It has been identified as a direct target gene of the transcription factor Myc, and its activation is relevant for the differentiation of primary human keratinocytes (Frye \& Watt, 2006). Mouse models of Nsun2 knockdown exhibit additional development defects, such as impaired cerebral cortex organization and immature skeleton, among others (Tuorto et al., 2012). NSUN2 was also involved in testis differentiation (Hussain et al., 2013). The molecular mechanisms connecting NSUN2 deficiencies and impaired cell differentiation were not identified.

\section{4 | Pseudouridine}

Pseudouridylation is the isomerization of the uridine base via breakage of the glycosidic bond, $180^{\circ}$ base-rotation and bond reformation (Hamma \& Ferré-D'Amaré, 2006) (Figure 1). It is the most frequent modification in total human RNA, although the mapping of pseudouridine $(\psi)$ in mRNAs was only recently addressed (Penzo et al., 2017). Methodological limitations have raised serious questions about the distribution and abundance of $\psi$, but the general consensus is that $\psi$ sites in mRNA are much less abundant than m6A (Schwartz et al., 2014). Besides mRNAs, non-coding RNAs (ncRNAs) have emerged as highly interesting targets with $\psi$ sites (Rintala-Dempsey \& Kothe, 2017). The enzymology associated with pseudouridylation is very complex. In eukaryotes, uridine is transformed into $\psi$ by a class of enzymes known as pseudouridylases. Pseudouridylases are represented in humans by pseudouridine synthases (PUS) and encoded by 13 genes. Human PUS enzymes are far less studied than their counterparts in other organisms, but recent discoveries allow a better identification of PUS enzymes, including those acting on mRNA (PUS1,
PUS3, PUS4, PUS6, PUS7 and PUS9) (Penzo et al., 2017). Their mode of action or potential redundancy in their functions has not yet been completely resolved (Carlile et al., 2014; Penzo et al., 2017). Currently, no specific eraser or reader associated with $\psi$ modifications has been identified (Barbieri \& Kouzarides, 2020).

It is well known that $\psi$ enhances the function of tRNA and rRNA by stabilizing the RNA structure as well as regulating the splicing process by modifying specific snRNAs (Barbieri \& Kouzarides, 2020; Carlile et al., 2014). The physiological relevance of $\psi$ in mRNA is more unclear with only a few indications of its role. Mutations in genes encoding human PUS enzymes cause inherited diseases affecting muscle and brain function which reinforced their emerging role as regulators of gene expression (Shaheen et al., 2019). Notably, $\psi$ content in $3^{\prime}$-UTR mRNA is regulated in response to environmental signals, such as serum starvation in human cells, suggesting a function in the flexible adaptation of the genetic code through inducible mRNA modifications (Carlile et al., 2014). A role in mRNA translation throughout the control of ribosome pausing and RNA localization has been also suggested (Carlile et al., 2014; Schwartz et al., 2014).

\section{5 | Adenosine-to-inosine editing}

Another RNA modification in mammals is the irreversible deamination of adenosine to inosine, a process also known as A-to-l editing (Figure 1). A-to-I editing occurs in a wide range of genomic sequences, from coding regions of mRNAs to non-coding regions (e.g. Alu repeats, pre-miRNAs or pri-miRNAs) (Nishikura, 2016). Inosine is interpreted at cellular level like a guanine, and consequently, A-to I editing could alter the biogenesis and/or function of miRNAs or mRNAs as well as proteins (Nishikura, 2016). However, a comparative study among animal A-to-I modifications revealed that non-coding parts of the genome were the main targets for the editing process. A role in protecting against activation of innate immunity by selftranscripts has been proposed (Eisenberg \& Levanon, 2018). A second type of A-to-I editing is hyper-editing, which could be understood as editing enriched regions (Porath et al., 2014). A large proportion of adenosines in close proximity to each other within the same transcript is a requisite for hyper-editing. In mammals, this class of editing is mostly associated with regions of repetitive sequences, intronic regions and 3' UTRs (Porath et al., 2017).

A-to-I editing is catalysed by adenosine deaminase acting on dsRNA. A family of proteins, ADAR. ADAR1 and ADAR2 are the catalytically active proteins, whereas ADAR3 lacks editing activity and may act as a negative regulator of ADAR1 and ADAR2 activity (Nishikura, 2016). Both ADAR1 and ADAR2 proteins have essential roles in cellular differentiation. In mammals, ADAR1 is widely expressed, especially in the myeloid component of the blood system, and plays a prominent role in promiscuous editing of long dsRNA (Zipeto et al., 2016). Additional studies indicate that ADAR1 forms a complex with Dicer to promote miRNA processing (Ota et al., 2013). ADAR2 has a higher expression in brain and is primarily required for site-specific editing of key transcripts for CNS development 
TABLE 1 Aberrant expression of RNA modifiers and RNA modifications linked to cancer

\begin{tabular}{|c|c|c|c|c|}
\hline $\begin{array}{l}\text { Gene } \\
\text { symbol }\end{array}$ & Activity & Consequences on cancer & Type of cancer & References \\
\hline \multicolumn{5}{|l|}{ Writers } \\
\hline METTL3 & m6A & $\begin{array}{l}\text { Overexpression is associated with increased } \\
\text { translation of oncogenic transcripts, such as MYC, } \\
\text { BCL2 or PTEN }\end{array}$ & AML & Vu et al. (2017) \\
\hline METTL3 & m6A & $\begin{array}{l}\text { Depletion in immunodeficient mice increases } \\
\text { differentiation of leukemic cells and decreased anti- } \\
\text { tumour effect }\end{array}$ & AML & Barbieri et al. (2017) \\
\hline METTL3 & m6A & $\begin{array}{l}\text { Up-regulation is a prognosis factor for adverse overall } \\
\text { survival. It regulates the m6A levels at the CDS of } \\
\text { the EMT gene SNAIL causing polysome-mediated } \\
\text { translation of snail mRNA }\end{array}$ & Liver cancer & Lin et al. (2019) \\
\hline METTL3 & m6A & $\begin{array}{l}\text { Overexpression is associated with increased } \\
\text { expression of EMT effectors such as MMP2 and N- } \\
\text { cadherin }\end{array}$ & Melanoma & Dahal et al. (2019) \\
\hline METTL3 & m6A & $\begin{array}{l}\text { Overexpression promotes the maturation of pri- } \\
\text { miR221/222 resulting in decreased expression of } \\
\text { the tumour suppressor gene PTEN }\end{array}$ & Bladder cancer & Han, Wang, et al. (2019) \\
\hline METTL3 & m6A & $\begin{array}{l}\text { Overexpression promotes the maturation of pri- } \\
\text { miRNA126 leading to decreased metastatic } \\
\text { potential in hepatocellular carcinoma }\end{array}$ & $\mathrm{HCC}$ & Ma et al. (2017) \\
\hline METTL3 & m6A & $\begin{array}{l}\text { Down-regulation results in activation of p-p38 and p- } \\
\text { ERK tumour suppressor pathway. }\end{array}$ & CRC & Deng et al. (2019) \\
\hline METTL14 & m6A & $\begin{array}{l}\text { Overexpression is associated with increased } \\
\text { expression of oncogenic mRNA targets such as MYB } \\
\text { and MYC }\end{array}$ & AML & Weng et al. (2018) \\
\hline METTL14 & m6A & $\begin{array}{l}\text { Hotspots genetic mutations lead to decreased } \\
\text { expression of the negative Akt regulator PHLPP2 } \\
\text { and increased expression of the positive Akt } \\
\text { regulator mTORC2 }\end{array}$ & Endometrial cancer & Liu et al. (2018) \\
\hline ALKBH3 & $\mathrm{m} 1 \mathrm{~A}$ & $\begin{array}{l}\text { Mediates increased mRNA abundance of CSF1, } \\
\text { promoting cell invasion without affecting cell } \\
\text { proliferation or migration }\end{array}$ & Ovarian and breast cancer & Woo and Chambers (2019) \\
\hline ALKBH3 & $\mathrm{m} 1 \mathrm{~A}$ & $\begin{array}{l}\text { Loss mediates abundance of collagen mRNAs } \\
\text { conferring poor prognosis }\end{array}$ & Hodgkin lymphoma & Esteve-Puig et al. (2020) \\
\hline NSUN2 & $\mathrm{m} 5 \mathrm{C}$ & $\begin{array}{l}\text { Overexpression is associated with low IGF-II } \\
\text { expression leading to higher overall and disease } \\
\text { progression-free survival }\end{array}$ & Ovarian cancer & Yang, Risch, et al. (2017) \\
\hline NSUN2 & $\mathrm{m} 5 \mathrm{C}$ & $\begin{array}{l}\text { Overexpression is associated with shorter overall } \\
\text { survival and a higher mortality risk. Its expression } \\
\text { has been proposed as a biomarker for the prediction } \\
\text { of response to immunotherapy through a } \\
\text { mechanism involving T-cell activation }\end{array}$ & HNSCC & Lu et al. (2020) \\
\hline NSUN2 & $\mathrm{m} 5 \mathrm{C}$ & $\begin{array}{l}\text { Stabilizes the oncogenic protein LINC01672 which } \\
\text { binds to chromatin regulator BPTF, resulting in } \\
\text { increased expression of MMP3 and MMP10 by } \\
\text { ERK1/2 activation }\end{array}$ & ESCC & Li, Li, et al. (2018) \\
\hline NSUN5 & $\mathrm{m} 5 \mathrm{C}$ & $\begin{array}{l}\text { Epigenetically silencing is associated with de- } \\
\text { methylation at the C } 3782 \text { position of } 28 \mathrm{~S} \text { rRNA } \\
\text { resulting in depletion of protein synthesis and } \\
\text { affecting the stress adaptive translational } \\
\text { programme }\end{array}$ & Glioblastoma & Janin et al. (2019) \\
\hline DKC1 & $\psi$ & $\begin{array}{l}\text { Overexpression is associated with tumour progression } \\
\text { and poor overall survival by the stabilization of the }\end{array}$ & Lung cancer & Penzo et al. (2015) \\
\hline
\end{tabular}
telomerase RNA component TERC 
TABLE 1 (Continued)

\begin{tabular}{|c|c|c|c|c|}
\hline $\begin{array}{l}\text { Gene } \\
\text { symbol }\end{array}$ & Activity & Consequences on cancer & Type of cancer & References \\
\hline DKC1 & $\psi$ & $\begin{array}{l}\text { Down-regulation by siRNA caused a decrease of } \mathrm{p} 53 \\
\text { mRNA translation and } \mathrm{p} 53 \text { protein inactivation }\end{array}$ & Breast cancer & Montanaro et al. (2010) \\
\hline PUS10 & $\psi$ & $\begin{array}{l}\text { Forms a complex with the ncRNA SRA1 to bind } \\
\text { retinoic acid receptor- } \gamma \text { and establishing the } \\
\text { transcriptional pre-initiation complex }\end{array}$ & $\begin{array}{l}\text { Melanoma and breast } \\
\text { cancer }\end{array}$ & Zhao et al. (2004) \\
\hline PUS10 & $\psi$ & $\begin{array}{l}\text { Participates in TRAIL-induced apoptosis by regulating } \\
\text { caspase- } 3 \text { activity }\end{array}$ & Prostate cancer & Jana et al. (2017) \\
\hline PUS10 & $\psi$ & $\begin{array}{l}\text { Depletion results in reduced expression of a large } \\
\text { number of mature miRNAs and concomitant } \\
\text { accumulation of unprocessed primary microRNAs } \\
\text { (pri-miRNAs) }\end{array}$ & Multiple human cell lines & Song et al. (2020) \\
\hline ADAR1 & A-to-I & $\begin{array}{l}\text { Overexpression is associated with increased } \\
\text { substitution of serine to glycine at residue } 367 \text { and } \\
\text { prevention of the degradation of the oncoproteins, } \\
\text { ornithine decarboxylase and cyclin D1 }\end{array}$ & $\mathrm{HCC}$ & Chen et al. (2013) \\
\hline ADAR1 & A-to-I & $\begin{array}{l}\text { Overexpression is associated with hyperediting of } \\
\text { FLNB and COPA }\end{array}$ & $\mathrm{HCC}, \mathrm{ESCC}$ & $\begin{array}{l}\text { Chan et al. (2014) and Qin } \\
\text { et al. (2014) }\end{array}$ \\
\hline ADAR1 & A-to-I & $\begin{array}{l}\text { Overexpression is associated with the induced } \\
\text { activation of the JAK/STAT pathway by type I IFNs }\end{array}$ & ESC & Zhang, Chen, Tang, et al. (2017) \\
\hline ADAR1 & A-to-I & $\begin{array}{l}\text { Overexpression is associated with expression of PU.1 } \\
\text { (myeloid transcription factor) inducing a malignant } \\
\text { reprogramming of embryonic stem cells }\end{array}$ & $\begin{array}{l}C M L \text { with } B C R-A B L \text { fusion } \\
\text { gene }\end{array}$ & Jiang et al. (2013) \\
\hline ADAR1 & A-to-I & $\begin{array}{l}\text { Overexpression is associated with enhanced editing } \\
\text { frequencies of target transcripts such as NEIL1 and } \\
\text { the oncogenic miR-381 }\end{array}$ & HNSCC & Anadón et al. (2016) \\
\hline ADAR1 & A-to-I & $\begin{array}{l}\text { Mediates editing of miRNAs (e.g. miR-455-5p) by a } \\
\text { mechanism involving the inhibition of the tumour } \\
\text { suppressor gene CPEB1 }\end{array}$ & Melanoma & Shoshan et al. (2015) \\
\hline ADAR1 & A-to-I & $\begin{array}{l}\text { Influences the phosphorylation level of crucial players } \\
\text { of mTOR signalling pathway enhancing oncogenesis }\end{array}$ & Gastric cancer & Dou et al. (2016) \\
\hline ADAR2 & A-to-I & Mediates editing of the tumour suppressor PODXL & Gastric cancer & Chan et al. (2016) \\
\hline ADAR2 & A-to-I & $\begin{array}{l}\text { Mediates editing and stabilization of IGFBP leading to } \\
\text { cell apoptosis and inhibition of tumour growth }\end{array}$ & ESCC & Chen et al. (2017) \\
\hline ADAR2 & A-to-I & $\begin{array}{l}\text { Overexpression is associated with regulation of cell } \\
\text { cycle proteins (e.g. SKP2, p21 and p27) and } \\
\text { inhibition of the cellular growth }\end{array}$ & $\begin{array}{l}\text { High-grade astrocytoma and } \\
\text { GBM }\end{array}$ & Galeano et al. (2013) \\
\hline ADAR2 & A-to-I & $\begin{array}{l}\text { Overexpression is associated with regulation of both } \\
\text { oncogenic and tumour suppressor (e.g. miRNAs } \\
\text { miR221, miR222 and miR-21) }\end{array}$ & GBM & Tomaselli et al. (2015) \\
\hline ADAR3 & A-to-I & $\begin{array}{l}\text { Overexpression is associated with compromised RNA } \\
\text { editing at the } \mathrm{Q} / \mathrm{R} \text { site of the transcript GRIA2 }\end{array}$ & $\begin{array}{l}\text { High-grade astrocytoma and } \\
\text { GBM }\end{array}$ & Oakes et al. (2017) \\
\hline \multicolumn{5}{|l|}{ Erasers } \\
\hline FTO & $\mathrm{m} 6 \mathrm{~A}$ & $\begin{array}{l}\text { Decreases m6A levels and increases the stability of } \\
\text { pro-tumourigenic genes, such as PDCD } 1, C X C R 4 \text { and } \\
\text { SOX10. It is also associated with resistance to } \\
\text { immunotherapy }\end{array}$ & Melanoma & Yang et al. (2019) \\
\hline FTO & $\mathrm{m} 6 \mathrm{~A}$ & $\begin{array}{l}\text { Decreases m6A levels in ASB2 and RARA mRNA } \\
\text { transcripts leading to inhibition of all-trans-retinoic } \\
\text { acid (ATRA)-induced AML cell differentiation and } \\
\text { promotion of leukemogenesis }\end{array}$ & AML & Li, Weng, et al. (2017) \\
\hline FTO & $\mathrm{m} 6 \mathrm{~A}$ & $\begin{array}{l}\text { It is inhibited by an oncometabolite produced in } \\
\text { IDH1/2-mutant tumours leading to increased m6A } \\
\text { content on specific targets }\end{array}$ & AML & Elkashef et al. (2017) \\
\hline
\end{tabular}


TABLE 1 (Continued)

\begin{tabular}{|c|c|c|c|c|}
\hline $\begin{array}{l}\text { Gene } \\
\text { symbol }\end{array}$ & Activity & Consequences on cancer & Type of cancer & References \\
\hline ALKBH5 & m6A & $\begin{array}{l}\text { Overexpression is correlated with poor prognosis. It is } \\
\text { implicated on the stabilization of the FOXM1 mRNA } \\
\text { transcript involved for the maintenance of } \\
\text { glioblastoma stem-cells properties and self-renewal }\end{array}$ & Glioblastoma & Zhang, Zhao, Zhou, et al. (2017) \\
\hline ALKBH5 & m6A & $\begin{array}{l}\text { Overexpression (stimulated by hypoxia-inducible } \\
\text { factors) results in gain of NANOG stability favouring } \\
\text { a stem cell phenotype }\end{array}$ & Breast cancer & Zhang et al. (2016) \\
\hline \multicolumn{5}{|l|}{ Readers } \\
\hline YTHDF1 & m6A & $\begin{array}{l}\text { Together with METTL3, it regulates the m6A levels at } \\
\text { the CDS of the EMT gene SNAIL causing polysome- } \\
\text { mediated translation of sNAIL mRNA }\end{array}$ & Liver cancer & Lin et al. (2019) \\
\hline YTHDF1 & m6A & $\begin{array}{l}\text { Depletion favours the therapeutic efficacy of PD-L1 } \\
\text { checkpoint blockade mediated by its role on the } \\
\text { antigen presentation in dendritic cells and } \\
\text { neoantigen-specific immunity }\end{array}$ & CCR and melanoma & Han, Liu, et al. (2019) \\
\hline YTHDF2 & m6A & $\begin{array}{l}\text { Overexpression is correlated with gain of expression of } \\
\text { the metastasis-related gene HIF-1 } \alpha\end{array}$ & CCR & Tanabe et al. (2016) \\
\hline YTHDF2 & m6A & $\begin{array}{l}\text { Together with FTO, it decreases m6A levels and } \\
\text { increases the stability of pro-tumourigenic genes, } \\
\text { such as PDCD1, CXCR4 and SOX10. It is also } \\
\text { associated with resistance to immunotherapy }\end{array}$ & Melanoma & Yang et al. (2019) \\
\hline YTHDF2 & m6A & $\begin{array}{l}\text { Overexpression is associated with diminished half-life } \\
\text { of TNFRSF2 transcript avoiding apoptosis in } \\
\text { leukaemia stem cells and promoting tumour } \\
\text { expansion }\end{array}$ & AML & Paris et al. (2019) \\
\hline YBX1 & $\mathrm{m} 5 \mathrm{C}$ & $\begin{array}{l}\text { Overexpression is correlated with increased m5C } \\
\text { levels at the PI3K-Akt35 and ERK-MAPK36 } \\
\text { oncogenic pathways }\end{array}$ & Bladder cancer & Chen et al. (2019) \\
\hline
\end{tabular}

Abbreviations: $\Psi$, pseudouridine; A-to-I, adenosine-to-inosine edition; AML, acute myeloid leukaemia; CDS, coding regions, CML, chronic myeloid leukaemia; CRC, colorectal cancer; EMT, epithelial-mesenchymal-transition; ESCC, oesophageal squamous cell carcinoma; GBM, glioblastoma multiforme; $\mathrm{HCC}$, hepatocellular carcinoma; HNSCC, head and neck squamous carcinoma; m1A, N1-methyladenosine; m5C, 5-methyl cytidine; m6A, N6-methyladenosine.

(Behm et al., 2017) and also plays a role in the control of the circadian clock (Terajima et al., 2017).

\section{4 | DE-REGULATED EPITRANSCRIPTOME IN CANCER}

Given the importance of RNA modifications in regulating RNA life cycle and their role in cell fate and normal human development (Esteller \& Pandolfi, 2017; Morena et al., 2018; Roundtree, Evans, et al., 2017), it is therefore not surprising that abnormal expression of the epitranscriptome leads to human diseases. In the last years, a number of studies have revealed that deregulated epitranscriptomes are associated with human pathologies, mainly, but not limited to, cancer (Table 1), through the deregulation of main tumourogenic pathways, including stem cell differentiation, cell invasion, immune responses, tissue renewal, viral infection or angiogenesis. In this section, we will summarize the major evidences of altered epitranscriptome associated with cancer. This is a growth area with major interest, so it is foreseeable that it will open up a wide range of possibilities for oncology research.

\section{1 | Alterations of N6-methyladenosine contents in cancer}

The study of m6A dysregulation has been the main focus in oncology. The expression of m6A methyltransferases is frequently altered in cancer, and the functional consequences could be compatible with oncogenic, but also tumour suppressor, properties depending on the tumour type (Barbieri \& Kouzarides, 2020; Rosselló-Tortella et al., 2020). Although the supporting evidence is still limited, this dual role in cancer seems to be determined by the cancer-specific downstream targets of m6A-related enzymes (Zheng et al., 2019).

An oncogenic role for METTL3 has been proposed in AML (Barbieri et al., 2017), clear cell renal cell carcinoma (Wang et al., 2020), gastric cancer (Yang et al., 2020) or pancreatic cancer (Taketo et al., 2017), among others. The role of METTL3-METTL14 
complex in the AML model has been widely reported (Barbieri et al., 2017; Vu et al., 2017). m6A methylation is essential for the maintenance of crucial mRNAs involved in the self-renewal of haematopoietic stem/progenitor cells, so that METTL3 overexpression contributes to the maintenance of undifferentiated leukemic cells (Barbieri et al., 2017; Vu et al., 2017). Mechanistically, overexpression of METTL3 results in increased translation of oncogenic transcripts such as MYC, BCL2 or PTEN, as firstly demonstrated in in vitro studies performed in the MOLM-13 cell line (Vu et al., 2017). In vivo assays performed in MMettl3-knockdown immunodeficient mice result in increased differentiation of leukemic cells and decreased anti-tumour effects (Barbieri et al., 2017), confirming the oncogenic role of METTL3. A MYC-dependent oncogenic role of METTL14 overexpression has been also described in AML (Weng et al., 2018). Epithelial-mesenchymal transition (EMT), a crucial process for cancer metastasis, has been also associated with METTL3 dysregulation. m6A in Snail CDS causes polysome-mediated translation of SNAIL mRNA in liver cancer cells (Lin et al., 2019). Moreover, the up-regulation of METTL3 and its reader YTHDF1 could be used as a prognosis factor for adverse overall survival of liver cancer patients (Lin et al., 2019). Overexpression of the EMT effectors metallopeptidase 2 (MMP2) and N-cadherin has been also observed in melanoma cells together with increased METTL3 expression (Dahal et al., 2019). Interestingly, the METTL3 mode of action also includes an effect on miRNA processing (Alarcón, Lee, et al., 2015). METTL3 promotes the maturation of miRNAs by interacting with the microprocessor protein DGCR8 (Alarcón, Lee, et al., 2015). In this model, METTL3 is able to dually modulate oncogenes or tumour suppressor genes by regulating the maturation of multiple miRNAs with pro- or anti-tumour activity. For example, METTL3 overexpression promotes the maturation of pri-miR221/222, resulting in decreased expression of the tumour suppressor gene PTEN, and leading to the proliferation of bladder cancer (Han, Wang, et al., 2019). On the contrary, METTL14-DGCR8 interaction positively modulates the primary miRNA126 process, in an m6 A-dependent manner, leading to decreased metastatic potential in hepatocellular carcinoma (Ma et al., 2017). Tumour suppressor functions on METTL3METTL14 complex have been identified (Cui et al., 2017; Deng et al., 2019; Liu et al., 2018). Human endometrial cancer carrying hotspot mutations in METTL14, and consequently reductions in $\mathrm{m6A}$ methylation, showed increased proliferation and tumourigenicity. Reductions in $\mathrm{m6A}$ methylation lead to decreased expression of the negative Akt regulator PHLPP2 and increased expression of the positive Akt regulator mTORC2 (Liu et al., 2018). METTL3 also acts as tumour-suppressor in colorectal cancer through the p38/ERK pathways (Deng et al., 2019).

In the case of altered m6A RNA demethylation in cancer, the first studies provide an oncogenic role for FTO in melanoma (lles et al., 2013; Yang et al., 2019). FTO decreases m6A methylation and increases the stability of pro-tumorigenic melanoma genes such as PDCD1, CXCR4 and SOX10, in a mechanism dependent on the m6A reader YTHDF2. A role for FTO in the promotion of resistance to immunotherapy (i.e. anti-PD-1) in melanoma therapy has been also demonstrated in mouse models (Yang et al., 2019). FTO also promotes tumour progression in $A M L$ with $t(11 \mathrm{q} 23) / M L L$ rearrangements, $\mathrm{t}(15 ; 17) / P M L-R A R A, \quad F L T 3-I T D$ and/or NPM1 mutations. FTO demethylase m6A levels in ASB2 and RARA mRNA transcripts leading to inhibition of all-trans-retinoic acid (ATRA)-induced AML cell differentiation and promotion of leukemogenesis (Li, Weng, et al., 2017). In contrast, it could have a suppressive effect in IDH1/2-mutant AML tumours. FTO is a 2-oxoglutarate-dependent dioxygenase that is competitively inhibited by the structurally related oncometabolite R-2-hydroxyglutarate, which aberrantly accumulates in IDH1/2-mutant AML tumours. This FOT inhibition results in an increase of $\mathrm{m} 6 \mathrm{~A}$ content at specific targets that contribute to leukaemia suppression (Elkashef et al., 2017). In sum, the FTO effect on tumourigenesis strongly depends on the genomic context and the downstream pathways that are involved.

The role of the m6A demethylase ALKBH5 has been well characterized in a glioblastoma model (Zhang, Zhao, Zhou, et al., 2017). ALKBH5 is highly expressed in glioblastoma stem-like cells and its target is the transcription factor FOXM1, which is crucial for the maintenance of glioblastoma stem-cells properties and self-renewal. As a result of loss of m6A in FOXM1 mRNA transcript, its stability is increased, the FOXM1 expression is enhanced and cell differentiation diminished. Interestingly, ALKBH5 expression is correlated with poor prognosis in glioblastoma (Zhang, Zhao, Zhou, et al., 2017). Similarly, ALKBH5 overexpression stimulated by hypoxia-inducible factors (HIF)- $1 \alpha-$ and HIF- $2 \alpha$ in breast cancer, demethylated the mRNA transcript of the pluripotency factor NANOG. The gain of NANOG stability favours a breast cancer stem cell phenotype (Zhang et al., 2016).

Finally, as previously mentioned, the $\mathrm{m} 6 \mathrm{~A}$ signal is interpreted by a set of reader proteins that exert their function in several biological pathways. Although the dysregulation of $\mathrm{m} 6 \mathrm{~A}$ readers should not result in changes in $\mathrm{m} 6 \mathrm{~A}$ patterns, alterations in the expression levels of these effector proteins could result in changes in the molecular function of the RNA modification. Furthermore, it still needs to be elucidated whether these readers have a crucial role in cancer independently of the m6A signal. The reader YTHDF1 has a suppression effect of the antigen presentation in dendritic cells facilitating stable neoantigen-specific immunity (Han, Liu, et al., 2019). In vivo studies using mouse models demonstrated that a loss of YTHDF1 in classical dendritic cells enhanced the cross-presentation of tumour antigens and the cross-priming of $\mathrm{CD}^{+} \mathrm{T}$ cells through mechanisms involving the control of mRNA translation of lysosomal cathepsins. Most important, the therapeutic efficacy of PD-L1 checkpoint blockade is enhanced after YTHDF1 abolition, highlighting the potential therapeutic application of YTHDF1 expression in immunotherapy (Han, Liu, et al., 2019). YTHDF2 reader is overexpressed in metastatic colorectal cancer, leading to gain of expression of the metastasis-related gene HIF- $1 \alpha$, of tumour cells both in vitro and in vivo. A potential biomarker role for predicting metastasis has been proposed (Tanabe et al., 2016). Although based on preliminary results, the prediction potential is extended to the HNRNPC reader (Liu et al., 2019). YTHDF2 is overexpressed in several subtypes of $A M L$ and is required 
for disease initiation as well as propagation in mouse and human AML (Paris et al., 2019). YTHDF2 decreases the half-life of TNF receptor Tnfrsf2 transcript avoiding apoptosis in leukaemia stem cells and promoting their expansion (Paris et al., 2019).

\section{2 | Alterations of N1-methyladenosine contents in cancer}

Most of the efforts for the elucidation of the role of m1A dysregulation in cancer mainly refer to tRNA demethylation. Recently, loss of m1A contents mediated by ALKBH3 increased the mRNA transcript abundance of the colony-stimulating factor, CSF1, promoting cell invasion without affecting cell proliferation or migration in ovarian and breast cancer cells (Woo \& Chambers, 2019). This study would suggest a pathological outcome of $\mathrm{m} 1 \mathrm{~A}$ dysregulation in mRNA species.

\section{3 | Alteration of 5-methylcytosine content in cancer}

Consistent with its role in cellular differentiation, alterations in NSUN2 expression has been associated with human cancer progression. Gain of protein expression of NSUN2 was quantified in many cancer types, including oesophageal squamous cell carcinoma (ESCC), stomach, liver, pancreas, uterine cervix, prostate, kidney, bladder, thyroid and breast cancer (Chellamuthu \& Gray, 2020). In some cases, NSUN2 expression has potential biomarker applications. Ovarian cancer patients with high NSUN2 expression and low IGF-II expression exhibit higher overall and disease progression-free survival (Yang Risch, et al., 2017). In contrast, NSUN2 up-regulation in head and neck squamous carcinoma (HNSCC) was associated with shorter overall survival and a higher mortality risk (Lu et al., 2018). Interestingly, NSUN2 expression has been proposed as a biomarker for the prediction of response to immunotherapy in HNSCC. The effect could be mediated by an association of NSUN2 expression and T-cell activation (Lu et al., 2020). In a similar manner to m6A or m1A RNA modifications, we are still far away from the understanding of the molecular pathways governing tumourigenesis. An elegant work aimed at identifying $5 \mathrm{mC}$ mRNA modifications at single-nucleotide resolution in human bladder carcinoma showed that hypermethylation of $\mathrm{m} 5 \mathrm{C}$ mRNAs is highly enriched in well-known cancer-related pathways, including PI3K-Akt35 and ERK-MAPK36, and the oncogene heparin binding growth factor (HBGF), resulting in enhanced mRNAs stabilization (Chen et al., 2019). In addition, authors found a $5 \mathrm{mC}$ reader named Y-box binding protein 1 (YBX1), whose expression is aberrantly increased in bladder cancer, providing new molecular clues on the dynamics of $5 \mathrm{mC}$ (Chen et al., 2019). A separate study described a role of NSUN2-dependent methylation in the stabilization of the oncogenic IncRNA NMR (LINC01672) in ESCC. As a result of its increased stability, NMR transcript could directly bind to chromatin regulator BPTF and potentially promote the expression of the metalloproteinase MMP3 and MMP10 by ERK1/2 activation ( $\mathrm{Li}, \mathrm{Li}$, et al., 2018). Conversely, other NSUN familiy members, such as NSUN5, exert tumour suppressor roles, being epigenetically inactivated in human brain tumours (Janin et al., 2019).

\subsection{Pseudouridine alterations associated with cancer}

Despite pseudouridylation biogenesis not being well understood, it is likely this modification plays a role in various physiological and pathological contexts. Unfortunately, its implication in disease and mode of action has been only partially explored up to now. Furthermore, most of the defects of $\Psi$ modification linked to cancer are mediated by its control of non-mRNA species, mainly rRNA or tRNA.

Altered dyskerin pseudouridine synthase (DKC1) activity has been recognized as a potential trigger for cancer onset in hereditary syndrome-associated tumours and sporadic cancers. DKC1 expression levels have been correlated with tumour progression and poor overall survival in breast cancer, hepatocellular carcinomas, lung and prostate cancers (Montanaro et al., 2006; Penzo et al., 2017; Sieron et al., 2009). Interestingly, the molecular consequences of dyskerin overexpression in cancer has been linked to the stabilization of the telomerase RNA component, TERC (Penzo et al., 2015). Additionally, impairment of DKC1 function has been associated with aberrant p53 mRNA translation and p53 inactivation in human breast cancer cells (Montanaro et al., 2010).

The pseudouridine synthase PUS1 has been associated with melanoma and breast cancer through the pseudouridylation activity on its target ncRNA, the steroid receptor RNA activator 1 (SRA1). SRA1-associated PUS1 then binds the nuclear receptor domains of target genes such as retinoic acid receptor- $\gamma$, to help establish the transcriptional pre-initiation complex (Zhao et al., 2004). Nevertheless, the molecular mechanisms underlying this phenomenon have not yet been clarified.

On the other hand, a mechanism involving the pseudouridine synthase PUS10 in TRAIL-induced apoptosis has been elucidated (Jana et al., 2017). PUS10 is exported from the nucleus to the mitochondria in the early stages of TRAIL-induced apoptosis. A feedback loop between PUS10 and caspase 3 is involved, in which active caspase- 3 is required for PUS10 export whereas the movement of PUS10 reciprocally amplifies caspase-3 activity (Jana et al., 2017). Whether the pseudouridine synthase is involved it is still uncertain. Recently, PUS10 was shown to bind to pre-miRNAs and interact with the microprocessor DROSHA-DGCR8 complex to promote miRNA biogenesis in multiple cell types. Mechanistically, this process is also independent of the catalytic activity of PUS10 (Song et al., 2020).

\subsection{Adenosine-to-inosine editing in cancer}

The wide-ranging biological effects of ADARs, affecting the basepairing properties of mRNA transcripts and ncRNAs and also altering 
codons after translation (and proteins), explains why their dysregulation results in many human diseases, including cancer. Alterations in ADAR activity have been found in many different cancers, including lung cancer, hepatocellular carcinoma, chronic myelogenous leukaemia, glioblastoma and melanoma (Chan et al., 2014; Chen et al., 2013; Jiang et al., 2013; Qin et al., 2014).

In hepatocellular carcinoma (HCC), ADAR1 is fundamental in the earlier stages of tumourigenesis. A-to-I editing of antizyme inhibitor 1 (AZIN1) transcripts leads to a substitution of serine for glycine at residue 367 , facilitating the tumorigenic phenotype and increased invasion properties (Chen et al., 2013). This effect is mediated by the prevention of the degradation of the ornithine decarboxylase (ODC1) and cyclin D1 oncoproteins. Additional A-to-I editing targets for ADAR1 in HCC has been proposed, including FLNB and COPA (Chan et al., 2014). AZIN1-dependent editing, together with FLNB A-to-I edition, is also involved in the pathogenesis of ESCC (Qin et al., 2014). Interestingly, type I IFNs and their associated JAK/STAT pathways, up-regulate ADAR1 expression resulting in aberrant A-to-I editing process in ESCC (Zhang, Chen, Tang, et al., 2017). In contrast, a tumour suppressor role for ADAR2 has been described and downregulation of ADAR2 enzyme has been linked to ESCC progression. In this work, the authors demonstrated that ADAR2 catalytic activity is necessary for the edition and stabilization of insulin-like growth factor binding protein 7 (IGFBP7) leading to cell apoptosis and inhibition of tumour growth (Chen et al., 2017). The mechanism by which ADAR1 expression is associated with CML involved the inflammatory pathway. In CML carrying the BCR-ABL fusion gene, the expression of IFN- $\gamma$ pathway genes promotes ADAR1 expression and editing activity (Jiang et al., 2013). Through in vitro genetic assays, authors demonstrated that over-expression of ADAR1 positively correlated with the expression of PU.1 (myeloid transcription factor) inducing a malignant reprogramming of embryonic stem cells (Jiang et al., 2013). In lung cancer, ADAR1 gene amplification and overexpression have been observed in HNSCC cell lines and primary tumours, and it has been proposed as a biomarker for prediction of poor outcome (Anadón et al., 2016). Mechanistically, ADAR1 overexpression enhances the editing frequencies of target transcripts such as NEIL1 (a DNA repair gene) and the oncogenic miR-381 (Anadón et al., 2016). ADAR1-mediated editing of miRNAs (e.g. miR-455-5p) has been also described for metastatic melanoma by a mechanism involving the inhibition of the tumour suppressor gene CPEB1 (Shoshan et al., 2015). In gastric cancer, $A D A R 1$ expression influences the phosphorylation level of crucial components of the mTOR signalling pathway (i.e. mTOR, p70S kinase and S6 ribosomal protein) enhancing oncogenesis (Dou et al., 2016), whereas ADAR2 exerts a tumour suppressor role through the A-to-I editing of the PODXL (podocalyxin-like) transcript (Chan et al., 2016).

Indeed, ADAR2 seems to be more associated with tumoursuppressor properties than ADAR1 in several types of cancers as it was widely described in highly aggressive brain tumours. In high-grade astrocytoma or glioblastoma multiforme (GBM), ADAR2 regulates key cell cycle proteins, such as SKP2, p21 and p27, which control the G1/M phase and inhibits cellular growth (Galeano et al., 2013). Also in
GBM, ADAR2 was involved in the editing of oncogenic and tumour suppressors, such as miRNAs miR221, miR222 and miR-21 (Tomaselli et al., 2015). A study of ADAR3 in glioblastoma revealed a potential binding competition between ADAR2 and ADAR3 to target specific transcripts and subsequently regulate their editing activity (Oakes et al., 2017). Overexpression of ADAR3 in astrocyte and astrocytoma cell lines inhibits RNA editing at the Q/R site of the transcript GRIA2. Most importantly, the relation between ADAR2 and ADAR3 expression contributes to the relative level of GRIA2 editing in primary tumour samples taken from glioblastoma patients (Oakes et al., 2017).

\section{5 | PHARMACOLOGICAL STRATEGIES AIM TO TARGET THE EPITRANSCRIPTOME}

Taking into consideration the dysregulation, as outlined above, of the epitranscriptome in cancer, the design and development of low MW compounds that potentially reverse defects in the epitranscriptome opens new and exciting opportunities for drug discovery in oncology (Table 2). Inevitably, the successful introduction of epigenetically based drugs into the clinic necessitates a model for chemical biology and drug discovery research on RNA-epitranscriptomics. Although the field of epitranscriptome-targeting is still in its beginnings, preclinical evidence of the benefits of RNA-modifying therapy are found in specific experimental models. Most important, several biotech companies are addressing the therapeutic potential of this promising field. Below, we will highlight the emerging results and challenges for the use of RNA modifications as feasible targets for cancer drug discovery.

\section{1 | RNA methyltransferase inhibitors}

There are several parallelisms between DNA and RNA methylation that support their exploitation within the framework of pharmacological inhibition. The most similar chemical modification is the addition of a methyl group at position 5 of cytidine resulting in 5-methylcytosine both in DNA or RNA structures. It is however not unreasonable to assume that current DNA methyltransferases affect the dynamics of m5C RNA. As mentioned before, drugs inhibiting DNA methylation, such as 5-azacytidine or decitabine, have been approved by the FDA and included the clinical treatments for haematological tumours (Berdasco \& Esteller, 2019). However, the vast majority ( $90 \%$ ) of 5 -azacytidine is incorporated into the RNA molecule and that DNA methylation status does not correlate with the clinical response to hypomethylating treatment. Whether the antiproliferative effect is mediated by RNA or DNA methylation is still under debate and further investigation is needed. Recently, a mechanism involving members of the RNA methyltransferases NSUN (NSUN1 and NSUN3) together with DNMT2 has been proposed as a mediator of responses to 5 -azacytidine, in a AML and myelodysplasic syndrome model (Cheng et al., 2018). Specifically, these authors proposed a mode of action that involves the formation of two chromatin complexes including distinct RNA modifiers to explain positive 

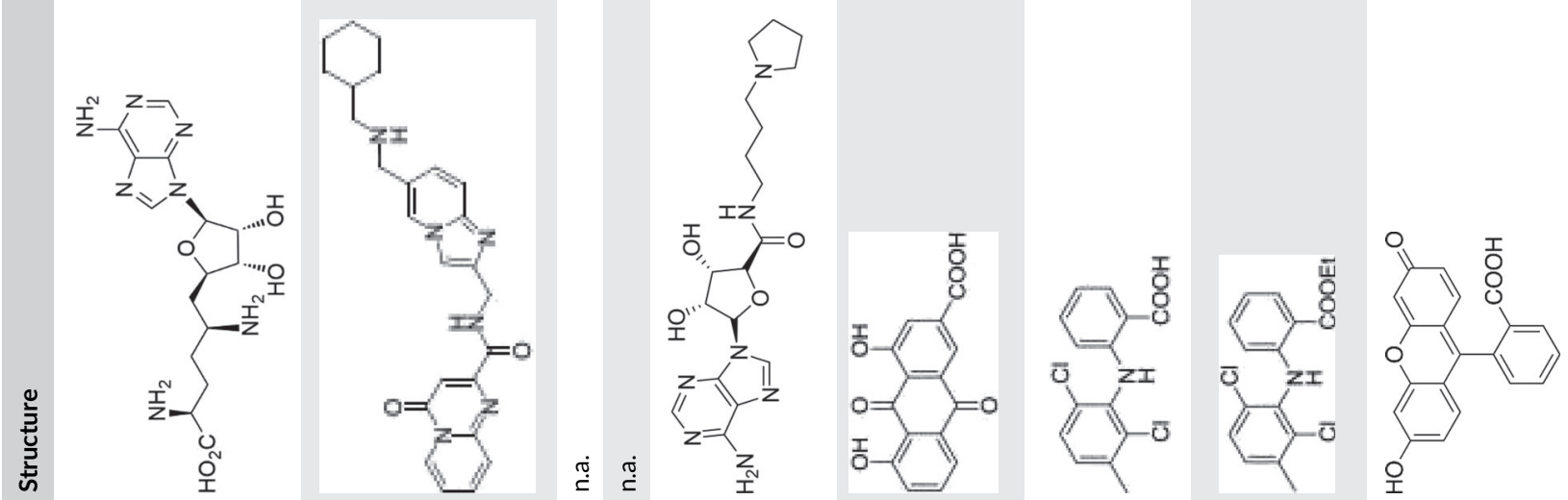

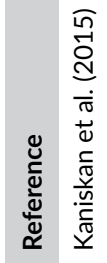
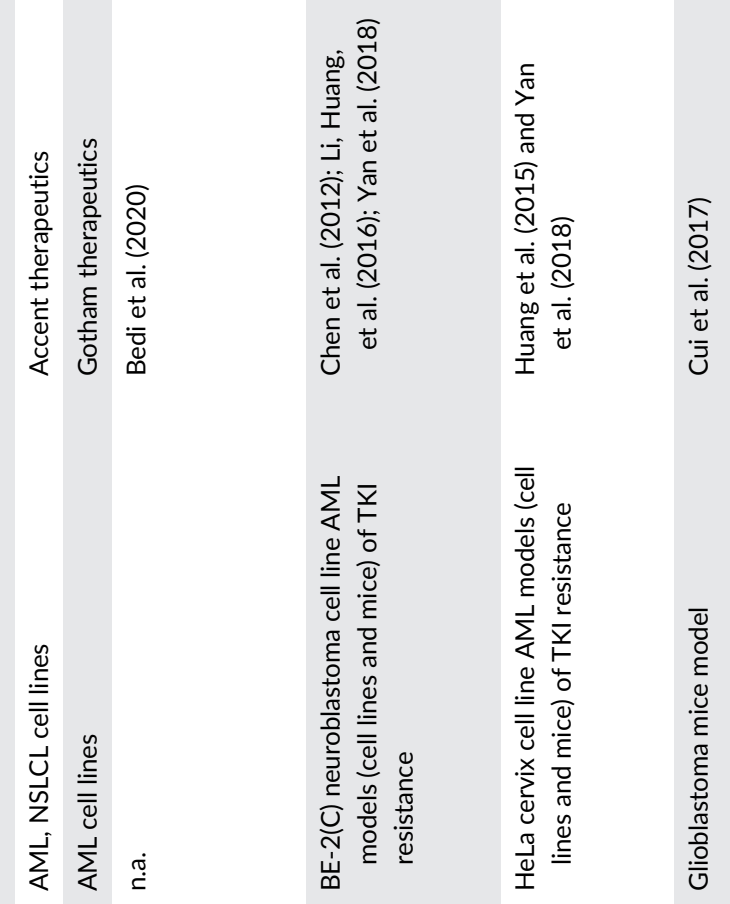

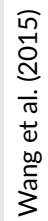
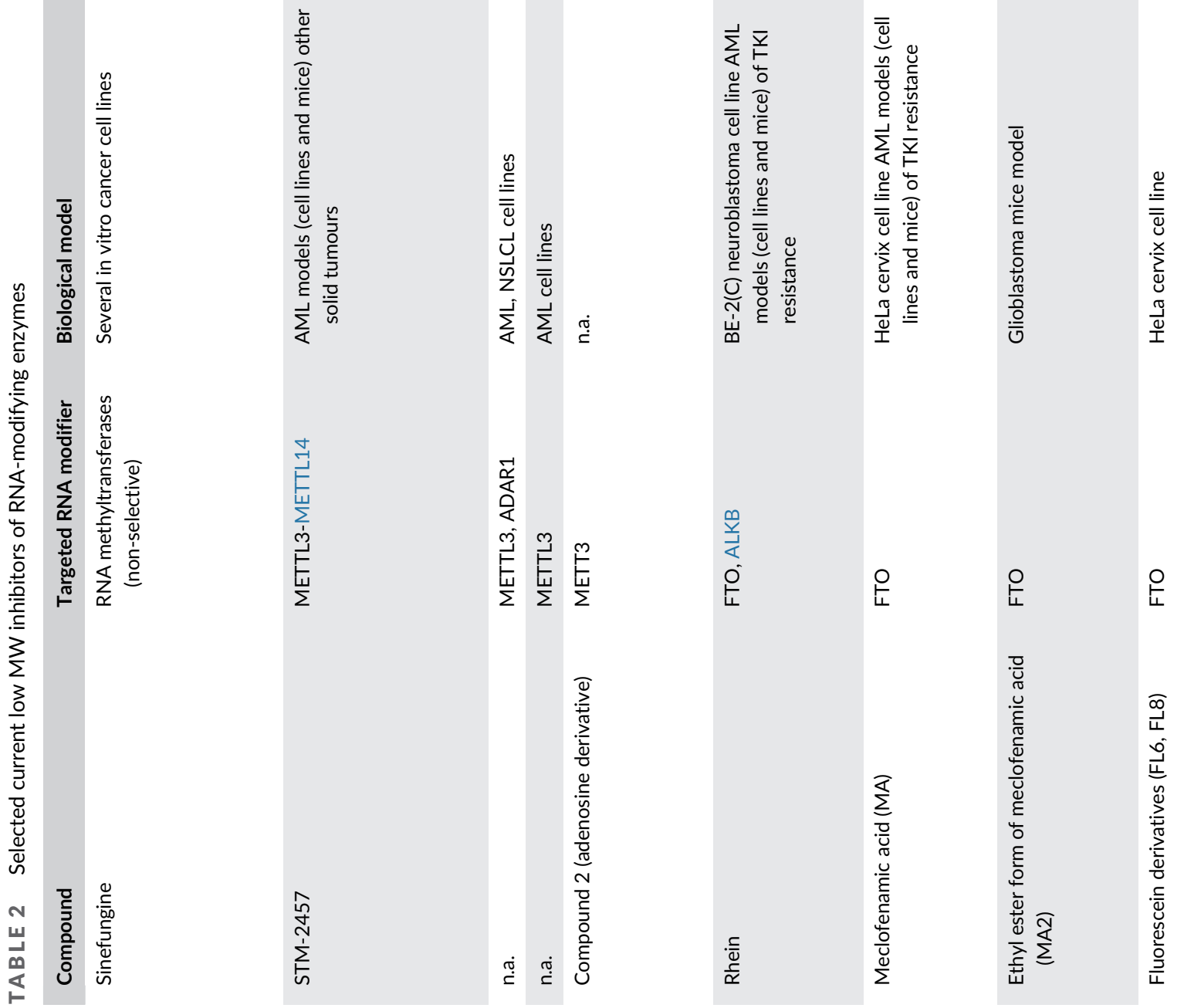

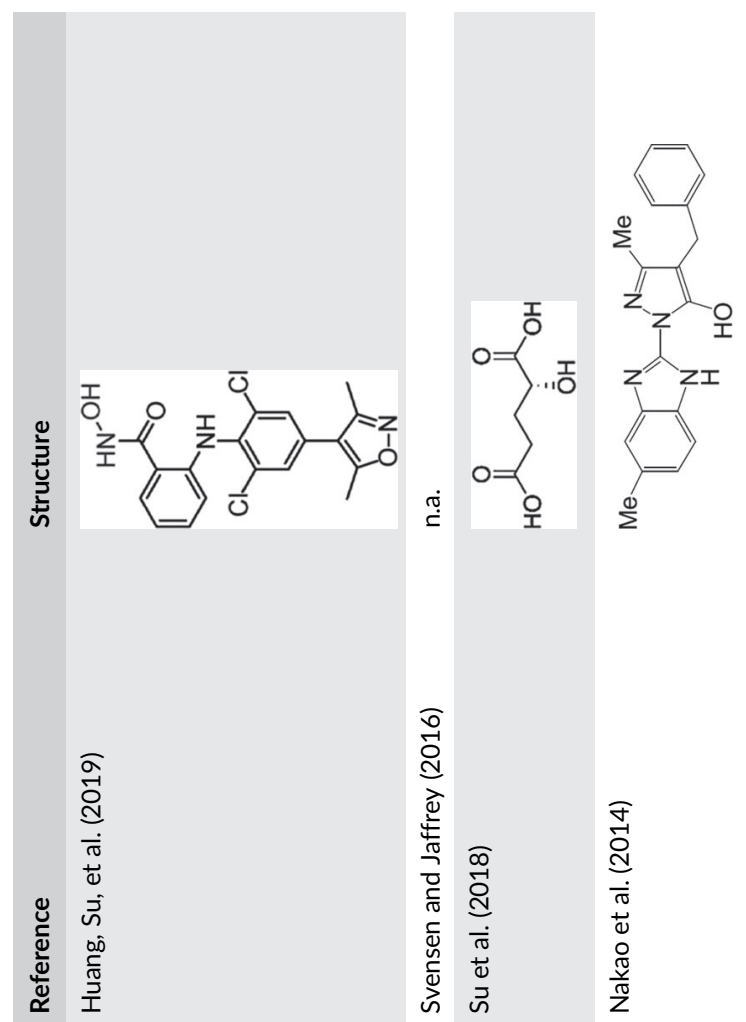

response or resistance to treatment with 5-azacytidine. In cells sensitive to 5-azacytidine, the reader hnRNPK directly recognized NSUN3, DNMT2 and CDK9/P-TEFb to recruit RNA-pol-II, resulting in an active conformation of chromatin in sensitive AML cells. In cells resistant to 5-azacytidine, the interaction of NSUN1 with the chromatin remodelling factor BRD4 (but not hnRNPK) and RNA pol-II results in an active chromatin structure that is resistant to 5-azacytidine. However, these 5-azacytidine-resistant cells are sensitive to the BRD4 inhibitor JQ1 and NSUN1 interference by siRNA (Cheng et al., 2018). Supporting evidence for the involvement of NSUN2 in the response to 5-azacytidine showed that NSUN2 and METTL1 deletion (by genetic knockdown) results in increased hypomethylating drug sensitivity in HeLa cells (Okamoto et al., 2014). Because acquired resistance to chemotherapy is a major problem in cancer treatments, unravelling the multiple molecular mechanisms that guides therapy response is an essential requirement in order to improve precision medicine in cancer.

Histone lysine methyltransferases (KMT) also contain a SAMbinding pocket and a substrate-binding domain that have been successfully targeted (Ganesan et al., 2019). The first attempt to inhibit KMT activity was based on the discovery that the natural product sinefungin reversibly competes with SAM for its binding site (Kaniskan et al., 2015). Thereafter, several potent SAM-mimetics have been developed as KMT inhibitors that are selective, by taking advantage of differences in the cofactor binding pocket. The DOT1L inhibitor, pimenostat, was the first KMT inhibitor to enter clinical trials for leukaemia therapy, followed by EZH2 inhibitors (GSK2816126 and tazemetostat) approved for B-cell lymphoma treatments (Berdasco \& Esteller, 2019). Although the protein structure of specific RNA methyltransferases has specific and unique features, like DOT1L, m5C and m6A RNA methyltransferases belong to the Rossmann fold family of methyltransferases. This similarity suggests that KMT inhibitors could be used as a starting point for the chemical design and drug development of inhibitors of RNA methyltransferases but, so far, this possibility has not been supported by any strong preclinical data..

Considering that $\mathrm{m} 6 \mathrm{~A}$ is the most universal RNA modification together with the well-defined aberrant m6A patterns associated with cancers, the research community has already drawn attention to the importance of developing the pharmacological manipulation of $\mathrm{m} 6 \mathrm{~A}$ methyltransferase activity. METTL3-METTL4 is up-regulated in cancers and down-regulation of METTL3 enzyme, using genetic manipulation by CRISPR-Cas9 technology, prevents cell proliferation and invasion in AML models, in vitro and in vivo (Barbieri et al., 2017). Consequently, drug developers from biotech companies have started the race for early drug discovery targeting RNA methyltransferases, mainly METTL3. Three companies, STORM Therapeutics (Cambridge, UK), Accent Therapeutics (MA, USA) and Gotham Therapeutics (NYC, USA), have METTL3 inhibitors in preclinical phases, ready for Phase I clinical trials (Cully, 2019). To date, the most advanced results have been achieved by STORM Therapeutics. In October 2020, STORM announced that its first-in-class drug candidate targeting METTL3 has been selected to enter human Phase I clinical trial as a therapy for refractory AML. Preclinical studies on a mouse model of AML showed 
that oral administration of STM-2457 reduced both splenomegaly and the number of circulating monocytes. Similarly, tumour growth was reduced in patient-derived-xenografts (PDX)-AML models after treatment with this METTL3 inhibitor (Cully, 2019; Yankova et al., 2021). The company is now studying possible application to solid tumours. Accent Therapeutics has started its drug discovery programme with an initial investment of $\$ 40 \mathrm{M}$ to optimize the selection of RNAmodifier inhibitors and they have found around 20 targets, with METTL3/METTL14 inhibitors for AML treatment at the front of their research (Boriack-Sjodin et al., 2019; Cully, 2019). Similarly, Gotham Therapeutics launched in October 2018 with a \$54 million programme is the third company with a METTL3 inhibitor in preclinical development for AML therapy (Cully, 2019).

Apart from these examples, discovery of METTL3-METTL14 inhibitors has also been explored in academia. Adenosine, one of the two moieties of SAM, is a SAM-competitive inhibitor of METTL3 activity. Recently, starting from a library of 4000 analogues and derivatives of the adenosine moiety of SAM and using high-throughput docking into METTL3 and protein X-ray crystallography, an adenosine derivative showed low $\mu \mathrm{M}$ potency and good ligand efficiency (Bedi et al., 2020). Interestingly, the authors showed that the ribose of adenosine can be replaced by other ring systems, opening new opportunities for additional modifications (Bedi et al., 2020). Further development in preclinical models is still needed to explore the biological effect and mode of action of these adenosine derivatives.

\section{2 | Inhibitors of RNA demethylases}

RNA demethylases also exhibit structural similarities with the protein lysine demethylases from the Jumonji C (JMJC) family. These are part of the 2-oxoglutarate and iron (II)-dependent dioxygenase family. This similarity is very interesting given that inhibitors of JMJC proteins are already available (Hauser et al., 2018) and that the mechanistic similarity between JMJC and RNA demethylases could facilitate the drug discovery for the inhibition of RNA modifications.

Interestingly, RNA demethylases have been targeted by specific low MW compounds. As m6A dysregulation has effects on normal development and disease, its inhibition has been the focus in the last few years (Table 2). A pioneer study of low MW inhibitors of the human FTO demethylase was achieved by an chemical optimization of the natural product rhein (Chen et al., 2012). Rhein competitively binds to the FTO active site in vitro and globally increases cellular m6A on mRNA in the BE-2(C) cell line (Chen et al., 2012). Rhein also binds to ALKBH2 and ALKBH3 m1A and m3C demethylases, respectively; however, different binding sites are involved for ALKB or FTO inhibition (Li, Huang, et al., 2016).

A selective inhibition of $\mathrm{m} 6 \mathrm{~A}$ demethylase FTO rather than ALKBH5 has been reported (Huang et al., 2015). The work was based on the identification of the differences in the displacement of $\mathrm{m} 6 \mathrm{~A}$ containing ssDNA binding to FTO and ALKBH5. This screen yielded meclofenamic acid, previously known and used as an antiinflammatory agent, as the best match to specifically inhibit FTO over
ALKBH5 (Huang et al., 2015). In vitro, treatment of HeLa cancer cells with the ethyl ester form of meclofenamate (MA2) increased m6A mRNA levels (Huang et al., 2015). Furthermore, the anti-proliferative effect of MA2 treatment has been tested in in vivo models of glioblastoma (Cui et al., 2017). MA2 increased mRNA m6A levels in glioblastoma-stem cells (GSC) leading to suppression of the GSCinitiated brain tumour development and prolonged the lifespan of GSC-engrafted mice (Cui et al., 2017). This result suggests that targeting m6A methylation could be a promising strategy for the treatment of glioblastoma. Using leukaemia in vitro and in vivo models, a role for the pharmacological inhibition of FTO to prevent resistance to tyrosine kinase inhibitor therapy has been demonstrated (Yan et al., 2018). Mechanistically, exposure to rhein or meclofenamate increased m6A and mRNA stability of survival and proliferation genes, such as BCL-2 or MERTK, improving the sensitivity of the tumour to the tyrosine kinase inhibitors nilotinib and PKC412 (Yan et al., 2018).

The knowledge gained from the studies of meclofenamate selectivity for FTO over ALKBH5, has facilitated the design of additional FTO inhibitors. In a later step, a study based on a screening of many fluorescent molecules with structures similar to meclofenamate revealed that fluorescein (and some of its derivatives) selectively inhibited FTO demethylation, as well as directly labelled FTO protein (Wang et al., 2015). Two fluorescein derivatives with improved cell permeability, FL6 and FL8, could efficiently inhibit FTO demethylation and modulate the level of m6A in the mRNA of living cells (Wang et al., 2015).

Research aimed at developing selective and cell-active low MW inhibitors of AlkB subfamilies of demethylases have also explored the nucleotide-binding site. instead of the 2-oxoglutarate-binding site (Toh et al., 2015). Compound 12 exhibits 30-fold to 130-fold selectivity for FTO over other AlkB subfamilies, and what is probably more interesting, the compound also discriminates against other human 2-oxoglutarate oxygenases, such as PHD2 and JMJD2A protein demethylases. Treatment with an ethyl ester derivative of compound 12 increases m6A in HeLa cells (Toh et al., 2015).

Using structure-based rational design, which maintains the benzyl carboxylic acid to keep meclofenamate selectivity for FTO but extends the dichloride-substituted benzene to a deeper pocket that could be fully occupied by a bulky ligand, two FTO inhibitors were developed (FB23 and FB23-2) (Huang, Su, et al., 2019). Based on the discovery that FB23 showed increased m6A levels due to FTO inhibition in in vitro $A M L$ cell lines, researchers have optimized the physicochemical property of FB23 and produced FB23-2 compound with a significantly improved anti-tumour effect, in vitro and in vivo. FB23-2 treatments reduced the proliferation of a panel of $A M L$ cell lines, but most importantly, FB23-2 also inhibits primary leukaemia stem cells in PDX -AML mouse models. Mechanistically, gain of m6A levels after FB23-2 treatment modulates mRNA transcripts associated with proliferation, such as those of MYC, CEBPA, RARA and ASB2 (Huang, Su, et al., 2019).

Additional FTO inhibitors were discovered using an elegant highthroughput screen using the fluorogenic methylated Broccoli substrate HTS assay (Svensen \& Jaffrey, 2016). These Broccoli assays are based on the construction of a fluorescent RNA-dye complex that 
appear non-fluorescent when it contains m6A but becomes fluorescent after demethylation. The study identified several selective compounds for FTO inhibition which increase m6A levels at FTO target mRNAs (bone morphogenetic protein 6 (BMP6) and ubiquitin C (UBC) in HEK293C cells (Svensen \& Jaffrey, 2016).

The possibilities extend beyond rational drug design as we learn more of the mode of action of the m6A-FTO axis. For example, the oncometabolite R--2-hydroxyglutarate ( $\mathrm{R}-2 \mathrm{HG}$ ) is produced at high levels in mutant isocitrate dehydrogenase 1/2 (IDH1/2) leukaemia cells (Su et al., 2018). However, R-2HG also has an anti-tumour effect through the inhibition of FTO activity. FTO inhibition results in a gain of m6A levels and the stabilization of the mRNA transcripts of MYC/ CEBPA, leading to the suppression of relevant proliferation pathways (Su et al., 2018).

Undoubtedly, the primary focus of attention is now on FTO inhibition. However, additional RNA demethylases could be 'druggable' targets. For example, the low MW compound 1-(5-methyl-1H-benzimidazol-2-yl)-4-benzyl-3-methylpyrazol-5-ol (HUHS015) inhibited the prostate cancer antigen-1 (PCA-1/ALKBH3) axis in prostate cancer cell lines and murine xenograft models of prostate cancer (Nakao et al., 2014).

\section{3 | Targeting other RNA modifications}

Epigenetic modifications of DNA molecules are interpreted by a set of reader proteins with essential functions. Most importantly, these readers for epigenetic marks are altered in human diseases, leading to the discovery of low MW inhibitors of their activity (Ganesan et al., 2019). Potent drug inhibitors have been identified for the H3K27me3 reader Polycomb protein EED from the Polycomb repressive complex 2 (PRC2) family (He et al., 2017). Like the YTF

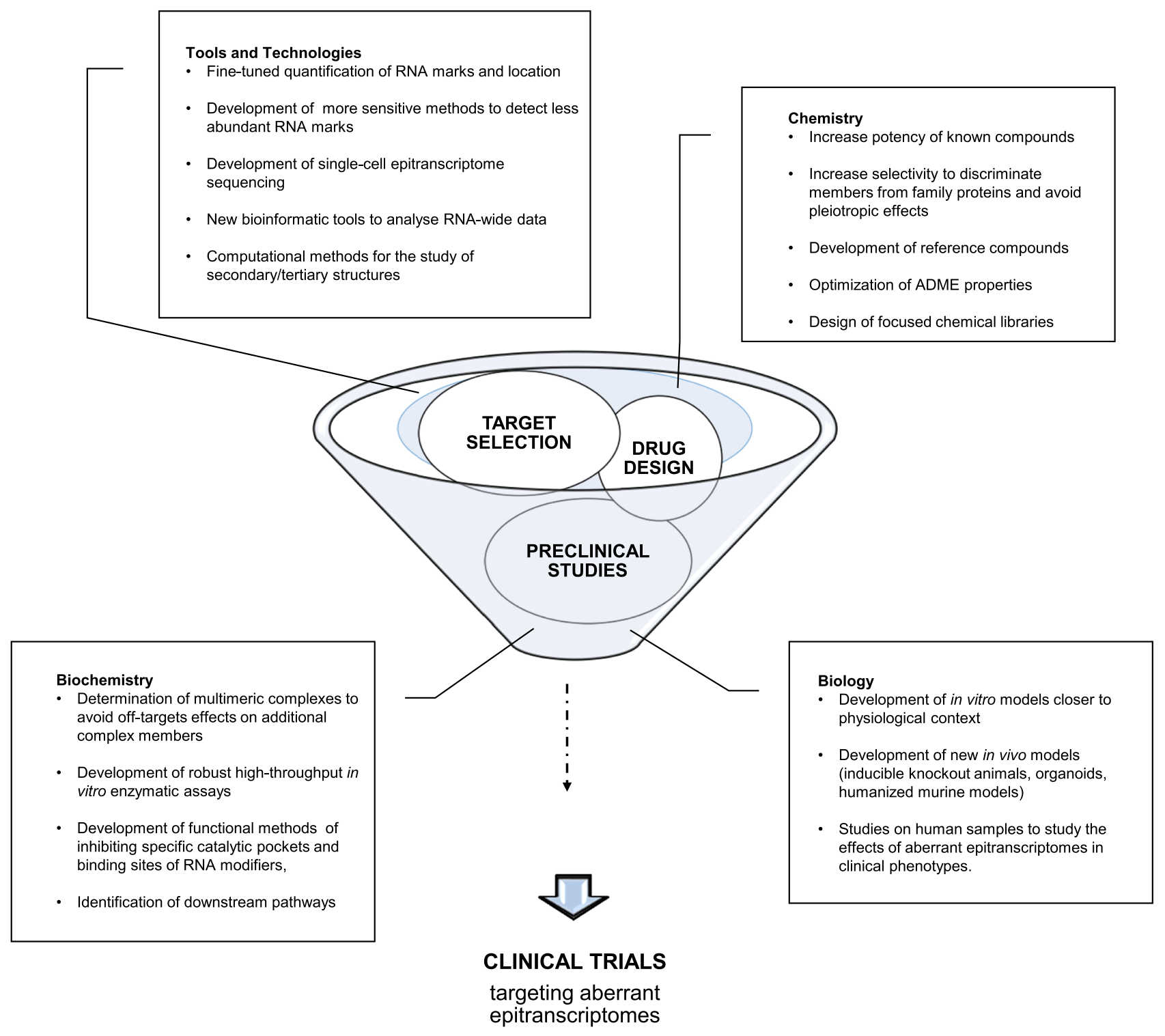

FIGURE 2 Challenges and difficulties for drug discovery targeting RNA-modifiers 
family of RNA methyl readers, Polycomb protein EED contains an aromatic cage crucial for the recognition of the methyl group. Whether the success of drug discovery associated with methyl-lysine readers could be translated to the methyl-RNA-reader field is still uncertain and unexplored. One barrier to the development of YTF inhibitors is that YTF members from the same family of proteins exhibit high structural homology. It still needs to be determined whether the application of Pan-YTF inhibitors could have a tissuespecific effect and contribute to increased specificity (Cully, 2019). Efforts to inhibit the $\mathrm{M} 7 \mathrm{G}$ reader, eukaryotic translation initiation factor 4E (elF4E), as a feasible target have been proposed (Soukarieh et al., 2016). Through its role in the regulation of mRNA translation of oncogenic pathways, elF4E is implicated in cell transformation, tumourigenesis and angiogenesis. Guanine-based inhibitors of elF4E were evaluated in in vitro cell-based assays and provided a set of compounds with inhibitory activity at physiological doses (Soukarieh et al., 2016).

There are unique RNA modifications that could not be compared with DNA or histone modifications. The RNA modifications involved in pseudouridylation or A-to-I editing have no precedents in drug discovery. However, chemical biology and drug discovery in this area require a better characterization of the modes of action and pathological implications in a context-specific manner. The $3^{\prime}$ terminal uridylyl transferase Zcchc11 (TUT4) is recruited to precursor let-7 RNA to selectively block let-7 miRNA biogenesis, a miRNA with tumour suppressor properties. Down-regulation of Let7 miRNA has been described in cancer. It is therefore of great application to develop an inhibitor for the uridylation of precursor Let-7 resulting in restored Let-7 expression in cancer (Lin \& Gregory, 2015). Using an automated high-throughput screen of $\sim 15,000$ chemicals, some compounds have been selected as putative TUTase inhibitors (Lin \& Gregory, 2015). The understanding of the TUT4-let-7 mediated inhibition is not addressed, so the consequences in preclinical models need to be determined.

In terms of pharmacological inhibition of the A-to-I edition, targeting the ADAR family of proteins could be a promising strategy for cancer therapy. As mentioned before, ADAR1 is involved in multiple cancer-related pathways, and loss of function of ADAR1 in tumour cells profoundly sensitizes tumours to anti-PD1 immunotherapy (Ishizuka et al., 2019). Consequently, a strategy to repress ADAR1 expression is particularly challenging. At present, no low MW compound targeting ADAR1 has been identified, but biotech companies such as Accent Therapeutics are known to be working on this target for NSCLC therapy (Cully, 2019). In a study of adenosine analogues, the 8-aza-adenosine compound showed inhibition of ADAR2 in vitro (Véliz et al., 2003).

\section{6 | CONCLUSION}

Rapidly accumulating evidence of the contribution of RNA modifications to cell differentiation and development and their dysregulation in cancer have emerged in the last few years (Barbieri \&
Kouzarides, 2020; Rosselló-Tortella et al., 2020). Although still in its infancy, the potential of pharmacological targeting of RNA modifiers for reversing aberrant epitranscriptomes has strongly energized research into the chemical biology and drug discovery in this field (Boriack-Sjodin et al., 2018). In Figure 2, we have highlighted some of the key limitations and challenges that will need to be addressed in the near future to improve drug discovery in this area of RNA biology (Figure 2).

It should be noticed that the field does not start from the zero, because the structures of key enzymes (writers and erasers) and reader proteins are currently well-characterized. This is a good starting point for guided and precise design of low MW compounds targeting these structures based on computational methods. To date, a sizeable number of epitranscriptomic inhibitors have been reported, but not all these inhibitors have demonstrated acceptable target potency or enzyme selectivity. Thus, there is still an unmet need to develop selective and more effective low MW inhibitors of RNA modifiers for therapeutic applications. Apart from rational chemical design approaches, we still need to learn more about the biochemistry of RNA modifiers, their ligand binding pockets and the downstream pathways.

A very important matter to consider is our current limited vision of the mode of action of RNA modifiers. In other words, we are establishing associations between two observations, for instance, an altered m6A level and a tumour-suppressive effect, but, to date, we cannot determine that such associations are causal. Most of the studies trying to establish phenotypic connections, applied approaches that involve genetic manipulation of the full RNA-related gene. These approaches do not allow us to determine whether the resulting phenotype is due to 'druggable' biochemical mechanisms (e.g. enzyme catalysis or ligand binding) or other less feasible targets linked to protein interactions, such as scaffolding, protein-protein interactions or chaperone mechanisms (Boriack-Sjodin et al., 2018). Or even less, whether the RNA modifications result in changes in secondary structures or protein-protein interactions is still uncertain.

More sophisticated biological approaches, other than cell-based assays, are essential to identify the functional effects of targeting the epitranscriptome. On the basis of what we have learned from epigenetic-based therapy, it is expected that RNA modifications work in multimeric protein complexes. Consequently, the translation of the results obtained from in vitro cell based assays do not replicate the physiological conditions of in vivo models. Animal models carrying RNA modification defects (e.g. inducible knockout or mutant mice for RNA-modifying enzymes) are a move in the right direction to unravel the physiological function of RNA modifications. Furthermore, as previously described (Cheng et al., 2018; Huang, Weng, et al., 2019), most of the actual RNA modifying enzymes share catalytic sites and cofactors with DNA and histone epigenetic machinery, and thus, drug-based intervention on RNA modifications are likely to induce unforeseen effects on other regulatory systems, including epigenetics.

Although we are seeing improvements, the high number of possible RNA modifications and the complexity of molecular pathways involved are still an impediment to the evaluation of the biological 
consequences of using low $\mathrm{MW}$ compounds to target the epitranscriptome (Jia et al., 2011; Wang et al., 2014). An aspect of intense debate is whether the ubiquitous nature of RNA modifications could increase the toxicity of associated drugs, as it would be extremely difficult to prevent a pleiotropic effect. This knowledge, undoubtedly, will require advances in the technical aspects. Methods of detecting RNA modification have shown a tremendous improvement, particularly because the development of valid methods for studying the epitranscriptome, on a wider scale, using NGS (Linder et al., 2015). Improvements to avoid methods dependent on antibody recognition or site-specific cleavage linked to radiolabelling, such as MAZTER-seq (Garcia-Campos et al., 2019) or m6A-REF-seq (Zhang et al., 2019), hold promise to allow a better quantification and precision of the epitranscriptome in specific contexts. Technological advances for the identification and quantification of low-abundance modifications of RNA, establishment of internal standards as controls or development of bioinformatic tools to generate, analyse, and standardize protocols should be also a priority to ensure the reliability of the data (Morena et al., 2018).

In overcoming these (and other) chemical, biological and technical barriers, we will have a better and clearer view of the epitranscriptome map, its contribution to signalling pathways and its role in human health and disease. With this comprehensive overview of 'epitranscriptome Science', the development of innovative therapeutic intervention of RNA modifications will be an exciting reality.

\subsection{Nomenclature of targets and ligands}

Key protein targets and ligands in this article are hyperlinked to corresponding entries in the IUPHAR/BPS Guide to PHARMACOLOGY (http://www.guidetopharmacology.org) and are permanently archived in the Concise Guide to PHARMACOLOGY 2019/20 (Alexander et al., 2019; Alexander, Cidlowski, et al., 2019; Alexander, Fabbro, et al., 2019a, 2019b; Alexander, Kelly et al., 2019).

\section{ACKNOWLEDGEMENTS}

We thank CERCA Programme/Generalitat de Catalunya for institutional support. Research at M.B. lab is supported by Instituto de Salud Carlos III co-funded by European Regional Development Funds (ERDF/FEDER) a way to build Europe (PI15/00638 and PI18/00910). Research at M.E. lab is supported by the Health Department PERIS-project no. SLT/002/16/00374 and AGAUR-projects no. 2017SGR1080 of the Catalan Government (Generalitat de Catalunya); Ministerio de Ciencia e Innovación ( $\mathrm{MCl}$ ), Agencia Estatal de Investigación (AEI) and European Regional Development Fund (ERDF) project no. RTI2018-094049-B-I00 and the Cellex Foundation; 'la Caixa' Banking Foundation (LCF/PR/GN18/51140001). M.E. is an ICREA Research Professor.

\section{CONFLICT OF INTERESTS}

M.B. discloses no conflict of interests. M.E. is a consultant for Ferrer and Quimatryx.

\section{ORCID}

María Berdasco (D) https://orcid.org/0000-0002-6750-0400

Manel Esteller (D) https://orcid.org/0000-0003-4490-6093

\section{REFERENCES}

Alarcón, C. R., Goodarzi, H., Lee, H., Liu, X., Tavazoie, S., \& Tavazoie, S. F. (2015). HNRNPA2B1 is a mediator of m6A-dependent nuclear RNA processing events. Cell, 162, 1299-1308.

Alarcón, C. R., Lee, H., Goodarzi, H., Halberg, N., \& Tavazoie, S. F. (2015). N6-methyladenosine marks primary microRNAs for processing. Nature, 519, 482-485.

Alexander, S. P. H., Christopoulos, A., Davenport, A. P., Kelly, E., Mathie, A., Peters, J. A., Veale, E. L., Armstrong, J. F., Faccenda, E., Harding, S. D., Pawson, A. J., Sharman, J. L., Southan, C., Davies, J. A., \& CGTP Collaborators. (2019). The concise guide to pharmacology 2019/20: G protein-coupled receptors. British Journal of Pharmacology, 176, S21-S141.

Alexander, S. P. H., Cidlowski, J. A., Kelly, E., Mathie, A., Peters, J. A., Veale, E. L., Armstrong, J. F., Faccenda, E., Harding, S. D., Pawson, A. J., \& Sharman, J. L. (2019). The Concise Guide to PHARMACOLOGY 2019/20: Nuclear hormone receptors. British Journal of Pharmacology, 176, S229-S246. https://doi.org/10.1111/ bph.14750

Alexander, S. P. H., Fabbro, D., Kelly, E., Mathie, A., Peters, J. A., Veale, E. L., Armstrong, J. F., Faccenda, E., Harding, S. D., Pawson, A. J., \& Sharman, J. L. (2019a). The Concise Guide to PHARMACOLOGY 2019/20: Catalytic receptors. British Journal of Pharmacology, 176, S247-S296. https://doi.org/10.1111/bph. 14751

Alexander, S. P. H., Fabbro, D., Kelly, E., Mathie, A., Peters, J. A., Veale, E. L., Armstrong, J. F., Faccenda, E., Harding, S. D., Pawson, A. J., Sharman, J. L., \& Southan, C. (2019b). The Concise Guide to PHARMACOLOGY 2019/20: Enzymes. British Journal of Pharmacology, 176, S297-S396. https://doi.org/10.1111/bph.14752

Alexander, S. P. H., Kelly, E., Mathie, A., Peters, J. A., Veale, E. L., Faccenda, E., Harding, S. D., Pawson, A. J., \& Sharman, J. L. (2019). THE CONCISE GUIDE TO PHARMACOLOGY 2019/20: Other Protein Targets. British Journal of Pharmacology, 176, S1-S2O. https://doi.org/ 10.1111/bph.14747

Allis, C. D., \& Jenuwein, T. (2016). The molecular hallmarks of epigenetic control. Nature Reviews. Genetics, 17, 487-500.

Anadón, C., Guil, S., Simó-Riudalbas, L., Moutinho, C., Setien, F., MartínezCardús, A., Moran, S., Villanueva, A., Calaf, M., Vidal, A., Lazo, P. A., Zondervan, I., Savola, S., Kohno, T., Yokota, J., de Pouplana, L. R., \& Esteller, M. (2016). Gene amplification-associated overexpression of the RNA editing enzyme ADAR1 enhances human lung tumorigenesis. Oncogene, 35, 4407-4413.

Ballestar, E., \& Li, T. (2017). New insights into the epigenetics of inflammatory rheumatic diseases. Nature Reviews Rheumatology, 13, 593-605.

Barbieri, I., \& Kouzarides, T. (2020). Role of RNA modifications in cancer. Nature Reviews. Cancer, 20, 303-322.

Barbieri, I., Tzelepis, K., Pandolfini, L., Shi, J., Millán-Zambrano, G., Robson, S. C., Aspris, D., Migliori, V., Bannister, A. J., Han, N., De Braekeleer, E., Ponstingl, H., Hendrick, A., Vakoc, C. R., Vassiliou, G. S., \& Kouzarides, T. (2017). Promoter-bound METTL3 maintains myeloid leukaemia by m6A-dependent translation control. Nature, 552, 126-131.

Bedi, R. K., Huang, D., Eberle, S. A., Wiedmer, L., Śledź, P., \& Caflisch, A. (2020). Small-molecule inhibitors of METTL3, the major human Epitranscriptomic writer. ChemMedChem, 15, 744-748.

Behm, M., Wahlstedt, H., Widmark, A., Eriksson, M., \& Öhman, M. (2017). Accumulation of nuclear ADAR2 regulates adenosine-to-inosine RNA editing during neuronal development. Journal of Cell Science, 130, 745-753. 
Berdasco, M., \& Esteller, M. (2019). Clinical epigenetics: Seizing opportunities for translation. Nature Reviews. Genetics, 20, 109-127.

Boccaletto, P., Machnicka, M. A., Purta, E., Piątkowski, P., Bagiński, B., Wirecki, T. K., de Crécy-Lagard, V., Ross, R., Limbach, P. A., Kotter, A., Helm, M., \& Bujnicki, J. M. (2018). MODOMICS: A database of RNA modification pathways. 2017 update. Nucleic Acids Research, 46, D303-D307.

Boriack-Sjodin, P. A., Gardino, A. K., Wynn, T. A., Buker, S. M., Laidlaw, M., Sickmier, E. A., Hodous, B. L., Case, A. W., Greene-Colozzi, A. E., Copeland, R. A., \& Ribich, S. (2019). Abstract A112: Drug discovery efforts on the RNA protein methyltransferase METTL3/METTL14. In Drug Design, (American Association for Cancer Research), A112-A112.

Boriack-Sjodin, P. A., Ribich, S., \& Copeland, R. A. (2018). RNA-modifying proteins as anticancer drug targets. Nature Reviews. Drug Discovery, 17, 435-453.

Carlile, T. M., Rojas-Duran, M. F., Zinshteyn, B., Shin, H., Bartoli, K. M., \& Gilbert, W. V. (2014). Pseudouridine profiling reveals regulated mRNA pseudouridylation in yeast and human cells. Nature, 515, 143-146.

Cavenagh, J. D., \& Popat, R. (2018). Optimal management of histone deacetylase inhibitor-related adverse events in patients with multiple myeloma: A focus on panobinostat. Clinical Lymphoma, Myeloma \& Leukemia, 18, 501-507.

Cenik, C., Chua, H. N., Singh, G., Akef, A., Snyder, M. P., Palazzo, A. F., Moore, M. J., \& Roth, F. P. (2017). A common class of transcripts with $5^{\prime}$-intron depletion, distinct early coding sequence features, and $\mathrm{N}$ 1-methyladenosine modification. RNA, 23, 270-283.

Chan, T. H. M., Lin, C. H., Qi, L., Fei, J., Li, Y., Yong, K. J., Liu, M., Song, Y., Chow, R. K. K., Ng, V. H. E., Yuan, Y.-F., Tenen, D. G., Guan, X.-Y., \& Chen, L. (2014). A disrupted RNA editing balance mediated by ADARs (adenosine DeAminases that act on RNA) in human hepatocellular carcinoma. Gut, 63, 832-843.

Chan, T. H. M., Qamra, A., Tan, K. T., Guo, J., Yang, H., Qi, L., Lin, J. S., Ng, V. H. E., Song, Y., Hong, H., Tay, S. T., Liu, Y., Lee, J., Rha, S. Y., Zhu, F., So, J. B. Y., Teh, B. T., Yeoh, K. G., Rozen, S., ... Chen, L. (2016). ADAR-mediated RNA editing predicts progression and prognosis of gastric cancer. Gastroenterology, 151, 637-650.e10.

Chellamuthu, A., \& Gray, S. G. (2020). The RNA methyltransferase NSUN2 and its potential roles in cancer. Cell, 9, 1758. https://doi.org/10. $3390 /$ cells9081758

Chen, B., Ye, F., Yu, L., Jia, G., Huang, X., Zhang, X., Peng, S., Chen, K., Wang, M., Gong, S., Zhang, R., Yin, J., Li, H., Yang, Y., Liu, H., Zhang, J., Zhang, H., Zhang, A., Jiang, H., ... Yang, C.-G. (2012). Development of cell-active N6-methyladenosine RNA demethylase FTO inhibitor Journal of the American Chemical Society, 134, 17963-17971.

Chen, L., Li, Y., Lin, C. H., Chan, T. H. M., Chow, R. K. K., Song, Y., Liu, M., Yuan, Y.-F., Fu, L., Kong, K. L., Qi, L., Li, Y., Zhang, N., Tong, A. H. Y., Kwong, D. L.-W., Man, K., Lo, C. M., Lok, S., Tenen, D. G., \& Guan, X.-Y. (2013). Recoding RNA editing of AZIN1 predisposes to hepatocellular carcinoma. Nature Medicine, 19, 209-216.

Chen, T., Hao, Y.-J., Zhang, Y., Li, M.-M., Wang, M., Han, W., Wu, Y., Lv, Y., Hao, J., Wang, L., Li, A., Yang, Y., Jin, K.-X., Zhao, X., Li, Y., Ping, X.-L., Lai, W.-Y., Wu, L.-G., Jiang, G., ... Zhou, Q. (2015). m6A RNA methylation is regulated by MicroRNAs and promotes reprogramming to pluripotency. Cell Stem Cell, 16, 289-301.

Chen, X., Li, A., Sun, B.-F., Yang, Y., Han, Y.-N., Yuan, X., Chen, R. X., Wei, W. S., Liu, Y., Gao, C. C., Chen, Y. S., Zhang, M., Ma, X. D., Liu, Z. W., Luo, J. H., Lyu, C., Wang, H. L., Ma, J., Zhao, Y. L., ... Yang, Y. G. (2019). 5-methylcytosine promotes pathogenesis of bladder cancer through stabilizing mRNAs. Nature Cell Biology, 21 978-990. https://doi.org/10.1038/s41556-019-0361-y

Chen, Y.-B., Liao, X.-Y., Zhang, J.-B., Wang, F., Qin, H.-D., Zhang, L., Shugart, Y. Y., Zeng, Y.-X., \& Jia, W.-H. (2017). ADAR2 functions as a tumor suppressor via editing IGFBP7 in esophageal squamous cell carcinoma. International Journal of Oncology, 50, 622-630.
Cheng, J. X., Chen, L., Li, Y., Cloe, A., Yue, M., Wei, J., Watanabe, K. A., Shammo, J. M., Anastasi, J., Shen, Q. J., Larson, R. A., He, C., Le Beau, M. M., \& Vardiman, J. W. (2018). RNA cytosine methylation and methyltransferases mediate chromatin organization and 5-azacytidine response and resistance in leukaemia. Nature Communications, 9, 1163. https://doi.org/10.1038/s41467-018-03513-4

Cossío, F. P., Esteller, M., \& Berdasco, M. (2020). Towards a more precise therapy in cancer: Exploring epigenetic complexity. Current Opinion in Chemical Biology, 57, 41-49.

Cui, Q., Shi, H., Ye, P., Li, L., Qu, Q., Sun, G., Sun, G., Lu, Z., Huang, Y., Yang, C. G., Riggs, A. D., He, C., \& Shi, Y. (2017). M6 a RNA methylation regulates the self-renewal and tumorigenesis of glioblastoma stem cells. Cell Reports, 18, 2622-2634. https://doi.org/ 10.1016/j.celrep.2017.02.059

Cully, M. (2019). Chemical inhibitors make their RNA epigenetic mark. Nature Reviews. Drug Discovery, 18, 892-894.

Dahal, U., Le, K., \& Gupta, M. (2019). RNA m6A methyltransferase METTL3 regulates invasiveness of melanoma cells by matrix metallopeptidase 2. Melanoma Research, 29, 382-389.

Dai, X., Wang, T., Gonzalez, G., \& Wang, Y. (2018). Identification of YTH domain-containing proteins as the readers for $\mathrm{N}$ 1-Methyladenosine in RNA. Analytical Chemistry, 90, 6380-6384.

Dai, Z., Ramesh, V., \& Locasale, J. W. (2020). The evolving metabolic landscape of chromatin biology and epigenetics. Nature Reviews Genetics, 21(12), 737-753.

Deng, R., Cheng, Y., Ye, S., Zhang, J., Huang, R., Li, P., Liu, H., Deng, Q., Wu, X., Lan, P., \& Deng, Y. (2019). m6A methyltransferase METTL3 suppresses colorectal cancer proliferation and migration through p38/ERK pathways. Oncotargets and Therapy, 12, 4391-4402.

Diesch, J., Zwick, A., Garz, A.-K., Palau, A., Buschbeck, M., \& Götze, K. S. (2016). A clinical-molecular update on azanucleoside-based therapy for the treatment of hematologic cancers. Clinical Epigenetics, 8, 71. https://doi.org/10.1186/s13148-016-0237-y

Dominissini, D., Moshitch-Moshkovitz, S., Schwartz, S., Salmon-Divon, M., Ungar, L., Osenberg, S., Cesarkas, K., Jacob-Hirsch, J., Amariglio, N., Kupiec, M., Sorek, R., \& Rechavi, G. (2012). Topology of the human and mouse m6A RNA methylomes revealed by m6A-seq. Nature, 485 , 201-206.

Dominissini, D., Nachtergaele, S., Moshitch-Moshkovitz, S., Peer, E., Kol, N., Ben-Haim, M. S., Dai, Q., Di Segni, A., Salmon-Divon, M., Clark, W. C., Zheng, G., Pan, T., Solomon, O., Eyal, E., Hershkovitz, V., Han, D., Doré, L. C., Amariglio, N., Rechavi, G., \& He, C. (2016). The dynamic N1-methyladenosine methylome in eukaryotic messenger RNA. Nature, 530, 441-446.

Dou, N., Yu, S., Ye, X., Yang, D., Li, Y., \& Gao, Y. (2016). Aberrant overexpression of ADAR1 promotes gastric cancer progression by activating mTOR/p70S6K signaling. Oncotarget, 7, 86161-86173.

Eisenberg, E., \& Levanon, E. Y. (2018). A-to-I RNA editing-Immune protector and transcriptome diversifier. Nature Reviews. Genetics, 19, 473-490.

Elkashef, S. M., Lin, A.-P., Myers, J., Sill, H., Jiang, D., Dahia, P. L. M., \& Aguiar, R. C. T. (2017). IDH mutation, competitive inhibition of FTO, and RNA methylation. Cancer Cell, 31, 619-620.

Esteller, M., \& Pandolfi, P. P. (2017). The epitranscriptome of noncoding RNAs in cancer. Cancer Discovery, 7, 359-368. https://doi.org/10. 1158/2159-8290.CD-16-1292

Esteve-Puig, R., Bueno-Costa, A., \& Esteller, M. (2020). Writers, readers and erasers of RNA modifications in cancer. Cancer Letters, 474, 127-137. https://doi.org/10.1016/j.canlet.2020.01.021

Frye, M., \& Watt, F. M. (2006). The RNA methyltransferase Misu (NSun2) mediates Myc-induced proliferation and is upregulated in tumors. Current Biology, 16, 971-981.

Fu, Y., Dominissini, D., Rechavi, G., \& He, C. (2014). Gene expression regulation mediated through reversible m6A RNA methylation. Nature Reviews. Genetics, 15, 293-306. 
Galeano, F., Rossetti, C., Tomaselli, S., Cifaldi, L., Lezzerini, M., Pezzullo, M., Boldrini, R., Massimi, L., Di Rocco, C. M., Locatelli, F., \& Gallo, A. (2013). ADAR2-editing activity inhibits glioblastoma growth through the modulation of the CDC14B/Skp2/p21/p27 axis. Oncogene, 32, 998-1009.

Ganesan, A. (2018). Epigenetic drug discovery: A success story for cofactor interference. Philosophical Transactions of the Royal Society B: Biological Sciences, 373, 20170069. https://doi.org/10.1098/rstb. 2017.0069

Ganesan, A., Arimondo, P. B., Rots, M. G., Jeronimo, C., \& Berdasco, M. (2019). The timeline of epigenetic drug discovery: From reality to dreams. Clinical Epigenetics, 11, 174. https://doi.org/10. 1186/s13148-019-0776-0

Garcia-Campos, M. A., Edelheit, S., Toth, U., Safra, M., Shachar, R., Viukov, S., Winkler, R., Nir, R., Lasman, L., Brandis, A., Hanna, J. H., Rossmanith, W., \& Schwartz, S. (2019). Deciphering the "m6A code" via antibody-independent quantitative profiling. Cell, 178, 731-747.e16.

Hamma, T., \& Ferré-D'Amaré, A. R. (2006). Pseudouridine synthases. Chemistry \& Biology, 13, 1125-1135.

Han, D., Liu, J., Chen, C., Dong, L., Liu, Y., Chang, R., Huang, X., Liu, Y., Wang, J., Dougherty, U., Bissonnette, M. B., Shen, B., Weichselbaum, R. R., Xu, M. M., \& He, C. (2019). Anti-tumour immunity controlled through mRNA m6A methylation and YTHDF1 in dendritic cells. Nature, 566, 270-274. https://doi.org/10.1038/ s41586-019-0916-X

Han, J., Wang, J., Yang, X., Yu, H., Zhou, R., Lu, H.-C., Yuan, W.-B., Lu, J.-c., Zhou, Z.-j., Lu, Q., Wei, J.-F., \& Yang, H. (2019). METTL3 promote tumor proliferation of bladder cancer by accelerating pri-miR221/222 maturation in m6A-dependent manner. Molecular Cancer, 18, 110. https://doi.org/10.1186/s12943-019-1036-9

Hauser, A.-T., Robaa, D., \& Jung, M. (2018). Epigenetic small molecule modulators of histone and DNA methylation. Current Opinion in Chemical Biology, 45, 73-85.

He, Y., Selvaraju, S., Curtin, M. L., Jakob, C. G., Zhu, H., Comess, K. M., Shaw, B., The, J., Lima-Fernandes, E., Szewczyk, M. M., Cheng, D., Klinge, K. L., Li, H.-Q., Pliushchev, M., Algire, M. A., Maag, D., Guo, J., Dietrich, J., Panchal, S. C., ... Pappano, W. N. (2017). The EED proteinprotein interaction inhibitor A-395 inactivates the PRC2 complex. Nature Chemical Biology, 13, 389-395.

Heck, A. M., Russo, J., Wilusz, J., Nishimura, E. O., \& Wilusz, C. J. (2020). YTHDF2 destabilizes $m 6$ A-modified neural-specific RNAs to restrain differentiation in induced pluripotent stem cells. RNA, 26, 739-755.

Hsu, P. J., Zhu, Y., Ma, H., Guo, Y., Shi, X., Liu, Y., Lu, Z., Shi, H., Wang, J., Cheng, Y., Luo, G., Dai, Q., Liu, M., Guo, X., Sha, J., Shen, B., \& He, C. (2017). Ythdc2 is an N6-methyladenosine binding protein that regulates mammalian spermatogenesis. Cell Research, 27, 1115-1127.

Huang, H., Weng, H., Sun, W., Qin, X., Shi, H., Wu, H., Zhao, B. S., Mesquita, A., Liu, C., Yuan, C. L., Hu, Y.-C., Hüttelmaier, S., Skibbe, J. R., Su, R., Deng, X., Dong, L., Sun, M., Li, C., Nachtergaele, S., ... Chen, J. (2018). Recognition of RNA N6-methyladenosine by IGF2BP proteins enhances mRNA stability and translation. Nature Cell Biology, 20, 285-295.

Huang, H., Weng, H., Zhou, K., Wu, T., Zhao, B. S., Sun, M., Chen, Z., Deng, X., Xiao, G., Auer, F., Klemm, L., Wu, H., Zuo, Z., Qin, X., Dong, Y., Zhou, Y., Qin, H., Tao, S., Du, J., ... Chen, J. (2019). Histone $\mathrm{H} 3$ trimethylation at lysine 36 guides m6A RNA modification co-transcriptionally. Nature, 567, 414-419.

Huang, T., Chen, W., Liu, J., Gu, N., \& Zhang, R. (2019). Genome-wide identification of mRNA 5-methylcytosine in mammals. Nature Structural \& Molecular Biology, 26, 380-388.

Huang, Y., Su, R., Sheng, Y., Dong, L., Dong, Z., Xu, H., Ni, T., Zhang, Z. S., Zhang, T., Li, C., Han, L., Zhu, Z., Lian, F., Wei, J., Deng, Q., Wang, Y., Wunderlich, M., Gao, Z., Pan, G., ... Yang, C.-G. (2019). Small-molecule targeting of oncogenic FTO demethylase in acute myeloid leukemia. Cancer Cell, 35, 677-691.e10.

Huang, Y., Yan, J., Li, Q., Li, J., Gong, S., Zhou, H., Gan, J., Jiang, H., Jia, G.-F., Luo, C., \& Yang, C.-G. (2015). Meclofenamic acid selectively inhibits FTO demethylation of m6A over ALKBH5. Nucleic Acids Research, 43, 373-384.

Hussain, S., Tuorto, F., Menon, S., Blanco, S., Cox, C., Flores, J. V., Watt, S., Kudo, N. R., Lyko, F., \& Frye, M. (2013). The mouse Cytosine-5 RNA Methyltransferase NSun2 is a component of the chromatoid body and required for testis differentiation. Molecular and Cellular Biology, 33, 1561-1570.

lles, M. M., Law, M. H., Stacey, S. N., Han, J., Fang, S., Pfeiffer, R., Harland, M., Macgregor, S., Taylor, J. C., Aben, K. K., Akslen, L. A., Avril, M.-F., Azizi, E., Bakker, B., Benediktsdottir, K. R., Bergman, W., Scarrà, G. B., Brown, K. M., Calista, D., ... GenoMEL Consortium; Q-MEGA and AMFS Investigators. (2013). A variant in FTO shows association with melanoma risk not due to BMI. Nature Genetics, 45, 428-432e1.

Ishizuka, J. J., Manguso, R. T., Cheruiyot, C. K., Bi, K., Panda, A., IrachetaVellve, A., Miller, B. C., du, P. P., Yates, K. B., Dubrot, J., Buchumenski, I., Comstock, D. E., Brown, F. D., Ayer, A., Kohnle, I. C., Pope, H. W., Zimmer, M. D., Sen, D. R., Lane-Reticker, S. K., ... Haining, W. N. (2019). Loss of ADAR1 in tumours overcomes resistance to immune checkpoint blockade. Nature, 565, 43-48. https://doi.org/10.1038/s41586-018-0768-9

Italiano, A., Soria, J.-C., Toulmonde, M., Michot, J.-M., Lucchesi, C., Varga, A., Coindre, J.-M., Blakemore, S. J., Clawson, A., Suttle, B., McDonald, A. A., Woodruff, M., Ribich, S., Hedrick, E., Keilhack, H., Thomson, B., Owa, T., Copeland, R. A., Ho, P. T. C., \& Ribrag, V. (2018). Tazemetostat, an EZH2 inhibitor, in relapsed or refractory B-cell nonHodgkin lymphoma and advanced solid tumours: A first-in-human, open-label, phase 1 study. The Lancet Oncology, 19, 649-659.

Jana, S., Hsieh, A. C., \& Gupta, R. (2017). Reciprocal amplification of caspase-3 activity by nuclear export of a putative human RNAmodifying protein, PUS10 during TRAIL-induced apoptosis. Cell Death \& Disease, 8, e3093-e3093.

Janin, M., Ortiz-Barahona, V., de Moura, M. C., Martínez-Cardús, A., Llinàs-Arias, P., Soler, M., Nachmani, D., Pelletier, J., Schumann, U., Calleja-Cervantes, M. E., \& Moran, S. (2019). Epigenetic loss of RNA-methyltransferase NSUN5 in glioma targets ribosomes to drive a stress adaptive translational program. Acta Neuropathologica, 138, 1053-1074. https://doi.org/10.1007/s00401-019-02062-4

Jia, G., Fu, Y., Zhao, X., Dai, Q., Zheng, G., Yang, Y., Yi, C., Lindahl, T., Pan, T., Yang, Y. G., \& He, C. (2011). N6-methyladenosine in nuclear RNA is a major substrate of the obesity-associated FTO. Nature Chemical Biology, 7, 885-887. https://doi.org/10.1038/nchembio.687

Jiang, Q., Crews, L. A., Barrett, C. L., Chun, H.-J., Court, A. C., Isquith, J. M., Zipeto, M. A., Goff, D. J., Minden, M., Sadarangani, A., Rusert, J. M., Dao, K.-H. T., Morris, S. R., Goldstein, L. S. B., Marra, M. A., Frazer, K. A., \& Jamieson, C. H. M. (2013). ADAR1 promotes malignant progenitor reprogramming in chronic myeloid leukemia. Proceedings of the National Academy of Sciences, 110, 1041-1046.

Jones, P. A., Ohtani, H., Chakravarthy, A., \& De Carvalho, D. D. (2019). Epigenetic therapy in immune-oncology. Nature Reviews. Cancer, 19, 151-161.

Kaniskan, H. Ü., Konze, K. D., \& Jin, J. (2015). Selective inhibitors of protein methyltransferases. Journal of Medicinal Chemistry, 58, 1596-1629.

Li, Q., Huang, Y., Liu, X., Gan, J., Chen, H., \& Yang, C.-G. (2016). Rhein inhibits AlkB repair enzymes and sensitizes cells to methylated DNA damage. The Journal of Biological Chemistry, 291, 11083-11093.

Li, X., Xiong, X., Wang, K., Wang, L., Shu, X., Ma, S., \& Yi, C. (2016). Transcriptome-wide mapping reveals reversible and dynamic N1-methyladenosine methylome. Nature Chemical Biology, 12, 311-316. https://doi.org/10.1038/nchembio.2040 
Li, X., Xiong, X., Zhang, M., Wang, K., Chen, Y., Zhou, J., Mao, Y., Lv, J., Yi, D., Chen, X.-W., Wang, C., Qian, S.-B., \& Yi, C. (2017). Base-resolution mapping reveals distinct $\mathrm{m} 1 \mathrm{~A}$ methylome in nuclearand mitochondrial-encoded transcripts. Molecular Cell, 68, 993-1005.e9.

Li, Y., Li, J., Luo, M., Zhou, C., Shi, X., Yang, W., Lu, Z., Chen, Z., Sun, N., \& $\mathrm{He}$, J. (2018). Novel long noncoding RNA NMR promotes tumor progression via NSUN2 and BPTF in esophageal squamous cell carcinoma. Cancer Letters, 430, 57-66.

Li, Z., Qian, P., Shao, W., Shi, H., He, X. C., Gogol, M., Yu, Z., Wang, Y., Qi, M., Zhu, Y., Perry, J. M., Zhang, K., Tao, F., Zhou, K., Hu, D., Han, Y., Zhao, C., Alexander, R., Xu, H., ... Li, L. (2018). Suppression of $\mathrm{m} 6 \mathrm{~A}$ reader Ythdf2 promotes hematopoietic stem cell expansion. Cell Research, 28, 904-917.

Li, Z., Weng, H., Su, R., Weng, X., Zuo, Z., Li, C., Huang, H., Nachtergaele, S., Dong, L., Hu, C., Qin, X., Tang, L., Wang, Y., Hong, G.-M., Huang, H., Wang, X., Chen, P., Gurbuxani, S., Arnovitz, S., ... Chen, J. (2017). FTO plays an oncogenic role in acute myeloid leukemia as a N6-methyladenosine RNA demethylase. Cancer Cell, 31, 127-141.

Lin, S., \& Gregory, R. I. (2015). Identification of small molecule inhibitors of Zcchc11 TUTase activity. RNA Biology, 12, 792-800.

Lin, X., Chai, G., Wu, Y., Li, J., Chen, F., Liu, J., Luo, G., Tauler, J., Du, J., Lin, S., He, C., \& Wang, H. (2019). RNA m6A methylation regulates the epithelial mesenchymal transition of cancer cells and translation of snail. Nature Communications, 10, 2065. https://doi.org/10.1038/ s41467-019-09865-9

Linder, B., Grozhik, A. V., Olarerin-George, A. O., Meydan, C., Mason, C. E., \& Jaffrey, S. R. (2015). Single-nucleotide-resolution mapping of m6A and m6Am throughout the transcriptome. Nature Methods, 12, 767-772.

Liu, J., Eckert, M. A., Harada, B. T., Liu, S.-M., Lu, Z., Yu, K., Tienda, S. M., Chryplewicz, A., Zhu, A. C., Yang, Y., Huang, J.-T., Chen, S.-M., Xu, Z.-G., Leng, X.-H., Yu, X.-C., Cao, J., Zhang, Z., Liu, J., Lengyel, E., \& $\mathrm{He}, \mathrm{C}$. (2018). m6A mRNA methylation regulates AKT activity to promote the proliferation and tumorigenicity of endometrial cancer. Nature Cell Biology, 20, 1074-1083.

Liu, N., Dai, Q., Zheng, G., He, C., Parisien, M., \& Pan, T. (2015). N6-methyladenosine-dependent RNA structural switches regulate RNA-protein interactions. Nature, 518, 560-564.

Liu, T., Li, C., Jin, L., Li, C., \& Wang, L. (2019). The prognostic value of m6A RNA methylation regulators in colon adenocarcinoma. Medical Science Monitor, 25, 9435-9445.

Lu, L., Gaffney, S. G., Cannataro, V. L., \& Townsend, J. (2020). Transfer RNA methyltransferase gene NSUN2 mRNA expression modifies the effect of $\mathrm{T}$ cell activation score on patient survival in head and neck squamous carcinoma. Oral Oncology, 101, 104554.

Lu, L., Zhu, G., Zeng, H., Xu, Q., \& Holzmann, K. (2018). High tRNA transferase NSUN2 gene expression is associated with poor prognosis in head and neck squamous carcinoma. Cancer Investigation, 36, 246-253.

Ma, J., Yang, F., Zhou, C., Liu, F., Yuan, J., Wang, F., Wang, T.-t., Xu, Q.-g., Zhou, W.-p., \& Sun, S.-h. (2017). METTL14 suppresses the metastatic potential of hepatocellular carcinoma by modulating N6-methyladenosine-dependent primary MicroRNA processing. Hepatology, 65, 529-543.

Meyer, K. D., Saletore, Y., Zumbo, P., Elemento, O., Mason, C. E., \& Jaffrey, S. R. (2012). Comprehensive analysis of mRNA methylation reveals enrichment in $3^{\prime}$ UTRs and near stop codons. Cell, 149, 1635-1646.

Montanaro, L., Brigotti, M., Clohessy, J., Barbieri, S., Ceccarelli, C., Santini, D., Teruya-Feldstein, J., Trerè, D., Pandolfi, P. P., \& Derenzini, M. (2006). Dyskerin expression influences the level of ribosomal RNA pseudo-uridylation and telomerase RNA component in human breast cancer. The Journal of Pathology, 210, 10-18.
Montanaro, L., Calienni, M., Bertoni, S., Rocchi, L., Sansone, P., Storci, G., Santini, D., Ceccarelli, C., Taffurelli, M., Carnicelli, D., Brigotti, M., Bonafè, M., Treré, D., \& Derenzini, M. (2010). Novel Dyskerinmediated mechanism of p53 inactivation through defective mRNA translation. Cancer Research, 70, 4767-4777.

Morena, F., Argentati, C., Bazzucchi, M., Emiliani, C., \& Martino, S. (2018). Above the epitranscriptome: RNA modifications and stem cell identity. Genes (Basel), 9, 329. https://doi.org/10.3390/ genes 9070329

Nakao, S., Mabuchi, M., Shimizu, T., Itoh, Y., Takeuchi, Y., Ueda, M., Mizuno, H., Shigi, N., Ohshio, I., Jinguji, K., Ueda, Y., Yamamoto, M., Furukawa, T., Aoki, S., Tsujikawa, K., \& Tanaka, A. (2014). Design and synthesis of prostate cancer antigen-1 (PCA-1/ALKBH3) inhibitors as anti-prostate cancer drugs. Bioorganic \& Medicinal Chemistry Letters, 24, 1071-1074.

Nishikura, K. (2016). A-to-I editing of coding and non-coding RNAs by ADARs. Nature Reviews. Molecular Cell Biology, 17, 83-96.

Oakes, E., Anderson, A., Cohen-Gadol, A., \& Hundley, H. A. (2017). Adenosine deaminase that acts on RNA 3 (ADAR3) binding to glutamate receptor subunit $B$ pre-mRNA inhibits RNA editing in glioblastoma. The Journal of Biological Chemistry, 292, 4326-4335.

Okamoto, M., Fujiwara, M., Hori, M., Okada, K., Yazama, F., Konishi, H., Konishi, H., Xiao, Y., Qi, G., Shimamoto, F., Ota, T., Temme, A., \& Tatsuka, M. (2014). tRNA modifying enzymes, NSUN2 and METTL1, determine sensitivity to 5 -fluorouracil in HeLa cells. PLoS Genetics, 10, e1004639.

Ota, H., Sakurai, M., Gupta, R., Valente, L., Wulff, B.-E., Ariyoshi, K., lizasa, H., Davuluri, R. V., \& Nishikura, K. (2013). ADAR1 forms a complex with dicer to promote MicroRNA processing and RNA-induced gene silencing. Cell, 153, 575-589.

Paris, J., Morgan, M., Campos, J., Spencer, G. J., Shmakova, A., Ivanova, I., Mapperley, C., Lawson, H., Wotherspoon, D. A., Sepulveda, C., Vukovic, M., Allen, L., Sarapuu, A., Tavosanis, A., Guitart, A. V., Villacreces, A., Much, C., Choe, J., Azar, A., ... Kranc, K. R. (2019). Targeting the RNA m6A reader YTHDF2 selectively compromises cancer stem cells in acute myeloid leukemia. Cell Stem Cell, 25, 137-148.e6.

Pendleton, K. E., Chen, B., Liu, K., Hunter, O. V., Xie, Y., Tu, B. P., \& Conrad, N. K. (2017). The U6 snRNA m6 a methyltransferase METTL16 regulates SAM Synthetase intron retention. Cell, 169, 824-835.e14.

Penzo, M., Guerrieri, A. N., Zacchini, F., Treré, D., \& Montanaro, L. (2017). RNA pseudouridylation in physiology and medicine: For better and for worse. Genes (Basel), 8(11), 301-314.

Penzo, M., Ludovini, V., Treré, D., Siggillino, A., Vannucci, J., Bellezza, G., Crinò, L., \& Montanaro, L. (2015). Dyskerin and TERC expression may condition survival in lung cancer patients. Oncotarget, 6, 21755-21760. https://doi.org/10.18632/oncotarget.4580

Porath, H. T., Carmi, S., \& Levanon, E. Y. (2014). A genome-wide map of hyper-edited RNA reveals numerous new sites. Nature Communications, 5, 4726-4735. https://doi.org/10.1038/ncomms5726

Porath, H. T., Knisbacher, B. A., Eisenberg, E., \& Levanon, E. Y. (2017). Massive A-to-I RNA editing is common across the Metazoa and correlates with dsRNA abundance. Genome Biology, 18(1), 185-196.

Prebet, T., Sun, Z., Figueroa, M. E., Ketterling, R., Melnick, A., Greenberg, P. L., Herman, J., Juckett, M., Wang, E. S., Smith, M. R., Malick, L., Paietta, E., Czader, M., Litzow, M., Gabrilove, J., Erba, H. P., Gore, S. D., \& Tallman, M. S. (2014). Prolonged administration of azacitidine with or without entinostat for myelodysplastic syndrome and acute myeloid leukemia with myelodysplasia-related changes: Results of the US leukemia intergroup trial E1905. Journal of Clinical Oncology, 32, 1242-1248.

Qin, Y.-R., Qiao, J.-J., Chan, T. H. M., Zhu, Y.-H., Li, F.-F., Liu, H., Fei, J., Li, Y., Guan, X. Y., \& Chen, L. (2014). Adenosine-to-inosine RNA editing mediated by ADARs in esophageal squamous cell carcinoma. 
Cancer Research, 74, 840-851. https://doi.org/10.1158/0008-5472. CAN-13-2545

Rintala-Dempsey, A. C., \& Kothe, U. (2017). Eukaryotic stand-alone pseudouridine synthases-RNA modifying enzymes and emerging regulators of gene expression? RNA Biology, 14, 1185-1196.

Rosselló-Tortella, M., Ferrer, G., \& Esteller, M. (2020). Epitranscriptomics in hematopoiesis and hematologic malignancies. Blood Cancer Discovery, 1, 26-31.

Roundtree, I. A., Evans, M. E., Pan, T., \& He, C. (2017). Dynamic RNA modifications in gene expression regulation. Cell, 169, 1187-1200.

Roundtree, I. A., \& He, C. (2016). RNA epigenetics-Chemical messages for posttranscriptional gene regulation. Current Opinion in Chemical Biology, 30, 46-51.

Roundtree, I. A., Luo, G.-Z., Zhang, Z., Wang, X., Zhou, T., Cui, Y., Sha, J., Huang, X., Guerrero, L., Xie, P., He, E., Shen, B., \& He, C. (2017). YTHDC1 mediates nuclear export of N6-methyladenosine methylated mRNAs. eLife, 6, e31311-e31338.

Safra, M., Sas-Chen, A., Nir, R., Winkler, R., Nachshon, A., Bar-Yaacov, D., Erlacher, M., Rossmanith, W., Stern-Ginossar, N., \& Schwartz, S. (2017). The m1A landscape on cytosolic and mitochondrial mRNA at single-base resolution. Nature, 551, 251-255.

Schwartz, S., Bernstein, D. A., Mumbach, M. R., Jovanovic, M., Herbst, R. H., León-Ricardo, B. X., Engreitz, J. M., Guttman, M., Satija, R., Lander, E. S., Fink, G., \& Regev, A. (2014). Transcriptomewide mapping reveals widespread dynamic-regulated pseudouridylation of ncRNA and mRNA. Cell, 159, 148-162.

Shaheen, R., Tasak, M., Maddirevula, S., Abdel-Salam, G. M. H., Sayed, I. S. M., Alazami, A. M., Al-Sheddi, T., Alobeid, E., Phizicky, E. M., \& Alkuraya, F. S. (2019). PUS7 mutations impair pseudouridylation in humans and cause intellectual disability and microcephaly. Human Genetics, 138, 231-239.

Shi, H., Wang, X., Lu, Z., Zhao, B. S., Ma, H., Hsu, P. J., Liu, C., \& He, C. (2017). YTHDF3 facilitates translation and decay of N6-methyladenosine-modified RNA. Cell Research, 27, 315-328.

Shoshan, E., Mobley, A. K., Braeuer, R. R., Kamiya, T., Huang, L., Vasquez, M. E., Salameh, A., Lee, H. J., Kim, S. J., Ivan, C., VelazquezTorres, G., Nip, K. M., Zhu, K., Brooks, D., Jones, S. J. M., Birol, I., Mosqueda, M., Wen, Y. Y., Eterovic, A. K., ... Bar-Eli, M. (2015). Reduced adenosine-to-inosine miR-455-5p editing promotes melanoma growth and metastasis. Nature Cell Biology, 17, 311-321. https://doi.org/10.1038/ncb3110

Sieron, P., Hader, C., Hatina, J., Engers, R., Wlazlinski, A., Müller, M., \& Schulz, W. A. (2009). DKC1 overexpression associated with prostate cancer progression. British Journal of Cancer, 101, 1410-1416. https:// doi.org/10.1038/sj.bjc.6605299

Śledź, P., \& Jinek, M. (2016). Structural insights into the molecular mechanism of the m6A writer complex. elife, 5, e18434-e18449. https:// doi.org/10.7554/eLife.18434

Song, J., Zhuang, Y., Zhu, C., Meng, H., Lu, B., Xie, B., Peng, J., Li, M., \& Yi, C. (2020). Differential roles of human PUS10 in miRNA processing and tRNA pseudouridylation. Nature Chemical Biology, 16, 160-169.

Soukarieh, F., Nowicki, M. W., Bastide, A., Pöyry, T., Jones, C., Dudek, K., Patwardhan, G., Meullenet, F., Oldham, N. J., Walkinshaw, M. D., Willis, A. E., \& Fischer, P. M. (2016). Design of nucleotide-mimetic and non-nucleotide inhibitors of the translation initiation factor elF4E: Synthesis, structural and functional characterisation. European Journal of Medicinal Chemistry, 124, 200-217.

Stein, E. M., Garcia-Manero, G., Rizzieri, D. A., Tibes, R., Berdeja, J. G., Savona, M. R., Jongen-Lavrenic, M., Altman, J. K., Thomson, B., Blakemore, S. J., Daigle, S. R., Waters, N. J., Suttle, A. B., Clawson, A., Pollock, R., Krivtsov, A., Armstrong, S. A., DiMartino, J., Hedrick, E., ... Tallman, M. S. (2018). The DOT1L inhibitor pinometostat reduces H3K79 methylation and has modest clinical activity in adult acute leukemia. Blood, 131, 2661-2669.
Su, R., Dong, L., Li, C., Nachtergaele, S., Wunderlich, M., Qing, Y., Deng, X., Wang, Y., Weng, X., Hu, C., Yu, M., Skibbe, J., Dai, Q., Zou, D., Wu, T., Yu, K., Weng, H., Huang, H., Ferchen, K., ... Chen, J. (2018). R-2HG exhibits anti-tumor activity by targeting $\mathrm{FTO} / \mathrm{m} 6 \mathrm{~A} / \mathrm{MYC} / \mathrm{CEBPA}$ signaling. Cell, 172, 90-105.e23.

Svensen, N., \& Jaffrey, S. R. (2016). Fluorescent RNA aptamers as a tool to study RNA-modifying enzymes. Cell Chemical Biology, 23, 415-425.

Taketo, K., Konno, M., Asai, A., Koseki, J., Toratani, M., Satoh, T., Doki, Y., Mori, M., Ishii, H., \& Ogawa, K. (2017). The epitranscriptome m6A writer METTL3 promotes chemo- and radioresistance in pancreatic cancer cells. International Journal of Oncology, 52(2), 621-629.

Tanabe, A., Tanikawa, K., Tsunetomi, M., Takai, K., Ikeda, H., Konno, J., Torigoe, T., Maeda, H., Kutomi, G., Okita, K., Mori, M., \& Sahara, H. (2016). RNA helicase YTHDC2 promotes cancer metastasis via the enhancement of the efficiency by which HIF-1 $\alpha$ mRNA is translated. Cancer Letters, 376, 34-42.

Tang, H., Fan, X., Xing, J., Liu, Z., Jiang, B., Dou, Y., Gorospe, M., \& Wang, W. (2015). NSun2 delays replicative senescence by repressing p27 (KIP1) translation and elevating CDK1 translation. Aging (Albany NY), 7, 1143-1155. https://doi.org/10.18632/aging.100860

Terajima, H., Yoshitane, H., Ozaki, H., Suzuki, Y., Shimba, S., Kuroda, S., Iwasaki, W., \& Fukada, Y. (2017). ADARB1 catalyzes circadian A-to-I editing and regulates RNA rhythm. Nature Genetics, 49, 146-151. https://doi.org/10.1038/ng.3731

Toh, J. D. W., Sun, L., Lau, L. Z. M., Tan, J., Low, J. J. A., Tang, C. W. Q., Cheong, E. J. Y., Tan, M. J. H., Chen, Y., Hong, W., Gao, Y.-G., \& Woon, E. C. Y. (2015). A strategy based on nucleotide specificity leads to a subfamily-selective and cell-active inhibitor of N6-methyladenosine demethylase FTO. Chemical Science, 6, 112-122.

Tomaselli, S., Galeano, F., Alon, S., Raho, S., Galardi, S., Polito, V. A., Presutti, C., Vincenti, S., Eisenberg, E., Locatelli, F., \& Gallo, A. (2015). Modulation of microRNA editing, expression and processing by ADAR2 deaminase in glioblastoma. Genome Biology, 16, 5. https://doi. org/10.1186/s13059-014-0575-z

Trixl, L., \& Lusser, A. (2019). The dynamic RNA modification 5-methylcytosine and its emerging role as an epitranscriptomic mark. Wiley Interdiscip. Rev. RNA, 10, e1510.

Tuorto, F., Liebers, R., Musch, T., Schaefer, M., Hofmann, S., Kellner, S., Frye, M., Helm, M., Stoecklin, G., \& Lyko, F. (2012). RNA cytosine methylation by Dnmt2 and NSun2 promotes tRNA stability and protein synthesis. Nature Structural \& Molecular Biology, 19, 900-905.

Véliz, E. A., Easterwood, L. M., \& Beal, P. A. (2003). Substrate analogues for an RNA-editing adenosine deaminase: Mechanistic investigation and inhibitor design. Journal of the American Chemical Society, 125, 10867-10876.

Villanueva, L., Álvarez-Errico, D., \& Esteller, M. (2020). The contribution of epigenetics to cancer immunotherapy. Trends in Immunology, 41, 676-691.

Vu, L. P., Pickering, B. F., Cheng, Y., Zaccara, S., Nguyen, D., Minuesa, G., Chou, T., Chow, A., Saletore, Y., MacKay, M., Schulman, J., Famulare, C., Patel, M., Klimek, V. M., Garrett-Bakelman, F. E., Melnick, A., Carroll, M., Mason, C. E., Jaffrey, S. R., \& Kharas, M. G. (2017). The N6-methyladenosine (m6A)-forming enzyme METTL3 controls myeloid differentiation of normal hematopoietic and leukemia cells. Nature Medicine, 23, 1369-1376.

Wang, J., Zhang, C., He, W., \& Gou, X. (2020). Effect of m6A RNA methylation regulators on malignant progression and prognosis in renal clear cell carcinoma. Frontiers in Oncology, 10(3), 1-13.

Wang, T., Hong, T., Huang, Y., Su, H., Wu, F., Chen, Y., Wei, L., Huang, W., Hua, X., Xia, Y., Xu, J., Gan, J., Yuan, B., Feng, Y., Zhang, X., Yang, C.-G., $\&$ Zhou, X. (2015). Fluorescein derivatives as bifunctional molecules for the simultaneous inhibiting and labeling of FTO protein. Journal of the American Chemical Society, 137, 13736-13739.

Wang, X., Lu, Z., Gomez, A., Hon, G. C., Yue, Y., Han, D., Fu, Y., Parisien, M., Dai, Q., Jia, G., Ren, B., Pan, T., \& He, C. (2014). 
N6-methyladenosine-dependent regulation of messenger RNA stability. Nature, 505, 117-120.

Weng, H., Huang, H., Wu, H., Qin, X., Zhao, B. S., Dong, L., Shi, H., Skibbe, J., Shen, C., Hu, C., Sheng, Y., Wang, Y., Wunderlich, M., Zhang, B., Dore, L. C., Su, R., Deng, X., Ferchen, K., Li, C., ... Chen, J. (2018). METTL14 inhibits hematopoietic stem/progenitor differentiation and promotes leukemogenesis via mRNA m6A modification. Cell Stem Cell, 22, 191-205.e9.

Woo, H.-H., \& Chambers, S. K. (2019). Human ALKBH3-induced m1A demethylation increases the CSF-1 mRNA stability in breast and ovarian cancer cells. Biochimica et Biophysica Acta, Gene Regulatory Mechanisms, 1862, 35-46.

Xiao, W., Adhikari, S., Dahal, U., Chen, Y.-S., Hao, Y.-J., Sun, B.-F., Sun, H.-Y., Li, A., Ping, X.-L., Lai, W.-Y., Wang, X., Ma, H.-L., Huang, C.-M., Yang, Y., Huang, N., Jiang, G.-B., Wang, H.-L., Zhou, Q., Wang, X.-J., ... Yang, Y.-G. (2016). Nuclear m6 a reader YTHDC1 regulates mRNA splicing. Molecular Cell, 61, 507-519.

Xing, J., Yi, J., Cai, X., Tang, H., Liu, Z., Zhang, X., Martindale, J. L., Yang, X., Jiang, B., Gorospe, M., \& Wang, W. (2015). NSun2 promotes cell growth via elevating cyclin-dependent kinase 1 translation. Molecular and Cellular Biology, 35, 4043-4052.

Yan, F., Al-Kali, A., Zhang, Z., Liu, J., Pang, J., Zhao, N., He, C., Litzow, M. R., \& Liu, S. (2018). A dynamic N6-methyladenosine methylome regulates intrinsic and acquired resistance to tyrosine kinase inhibitors. Cell Research, 28, 1062-1076.

Yang, D.-D., Chen, Z.-H., Yu, K., Lu, J.-H., Wu, Q.-N., Wang, Y., Ju, H.-Q., Xu, R.-H., Liu, Z.-X., \& Zeng, Z.-L. (2020). METTL3 promotes the progression of gastric cancer via targeting the MYC pathway. Frontiers in Oncology, 10(115), 1-12.

Yang, J., Risch, E., Zhang, M., Huang, C., Huang, H., \& Lu, L. (2017). Association of tRNA methyltransferase NSUN2/IGF-II molecular signature with ovarian cancer survival. Future Oncology, 13, 1981-1990.

Yang, S., Wei, J., Cui, Y.-H., Park, G., Shah, P., Deng, Y., Aplin, A. E., Lu, Z., Hwang, S., He, C., \& He, Y. Y. (2019). m6A mRNA demethylase FTO regulates melanoma tumorigenicity and response to anti-PD-1 blockade. Nature Communications, 10(1), 2782-2795. https://doi.org/10. 1038/s41467-019-10669-0

Yang, X., Yang, Y., Sun, B.-F., Chen, Y.-S., Xu, J.-W., Lai, W.-Y., Li, A., Wang, X., Bhattarai, D. P., Xiao, W., Sun, H. Y., Zhu, Q., Ma, H. L., Adhikari, S., Sun, M., Hao, Y. J., Zhang, B., Huang, C. M., Huang, N., ... Yang, Y. G. (2017). 5-methylcytosine promotes mRNA export-NSUN2 as the methyltransferase and ALYREF as an $\mathrm{m} 5 \mathrm{C}$ reader. Cell Research, 27, 606-625. https://doi.org/10.1038/cr.2017.55

Yankova, E., Blackaby, W., Albertella, M., Rak, J., De Braekeleer, E., Tsagkogeorga, G., Pilka, E. S., Aspris, D., Leggate, D., Hendrick, A. G., Webster, N. A., Andrews, B., Fosbeary, R., Guest, P., Irigoyen, N., Eleftheriou, M., Gozdecka, M., Dias, J. M. L., Bannister, A. J., .. Kouzarides, T. (2021). Small-molecule inhibition of METTL3 as a strategy against myeloid leukaemia. Nature, 593, 597-601. https://doi.org/ 10.1038/s41586-021-03536-w

Zhang, C., Chen, Y., Sun, B., Wang, L., Yang, Y., Ma, D., Lv, J., Heng, J., Ding, Y., Xue, Y., Lu, X., Xiao, W., Yang, Y.-G., \& Liu, F. (2017). m6A modulates haematopoietic stem and progenitor cell specification. Nature, 549, 273-276.
Zhang, C., Samanta, D., Lu, H., Bullen, J. W., Zhang, H., Chen, I., He, X., \& Semenza, G. L. (2016). Hypoxia induces the breast cancer stem cell phenotype by HIF-dependent and ALKBH5-mediated m6 A-demethylation of NANOG mRNA. Proceedings of the National Academy of Sciences, 113, E2047-E2056.

Zhang, J., Chen, Z., Tang, Z., Huang, J., Hu, X., \& He, J. (2017). RNA editing is induced by type I interferon in esophageal squamous cell carcinoma. Tumor Biology, 39, 101042831770854.

Zhang, S., Zhao, B. S., Zhou, A., Lin, K., Zheng, S., Lu, Z., Chen, Y., Sulman, E. P., Xie, K., Bögler, O., Majumder, S., He, C., \& Huang, S. (2017). M6 a demethylase ALKBH5 maintains tumorigenicity of glioblastoma stem-like cells by sustaining FOXM1 expression and cell proliferation program. Cancer Cell, 31, 591-606.e6.

Zhang, Z., Chen, L.-Q., Zhao, Y.-L., Yang, C.-G., Roundtree, I. A., Zhang, Z., Zhang, Z., Ren, J., Xie, W., He, C., \& Luo, G.-Z. (2019). Single-base mapping of $\mathrm{m} 6$ a by an antibody-independent method. Science Advances, 5, eaax0250.

Zhao, X., Patton, J. R., Davis, S. L., Florence, B., Ames, S. J., \& Spanjaard, R. A. (2004). Regulation of nuclear receptor activity by a pseudouridine synthase through posttranscriptional modification of steroid receptor RNA activator. Molecular Cell, 15, 549-558.

Zheng, G., Dahl, J. A., Niu, Y., Fedorcsak, P., Huang, C.-M., Li, C. J., Vågbø, C. B., Shi, Y., Wang, W.-L., Song, S.-H., Lu, Z., Bosmans, R. P. G., Dai, Q., Hao, Y.-J., Yang, X., Zhao, W.-M., Tong, W.M., Wang, X.-J., Bogdan, F., ... He, C. (2013). ALKBH5 is a mammalian RNA demethylase that impacts RNA metabolism and mouse fertility. Molecular Cell, 49, 18-29.

Zheng, W., Dong, X., Zhao, Y., Wang, S., Jiang, H., Zhang, M., Zheng, X., \& Gu, M. (2019). Multiple functions and mechanisms underlying the role of METTL3 in human cancers. Frontiers in Oncology, 9(1403), 1-9. https://doi.org/10.3389/fonc.2019.01403

Zhong, X., Yu, J., Frazier, K., Weng, X., Li, Y., Cham, C. M., Dolan, K., Zhu, X., Hubert, N., Tao, Y., Lin, F., Martinez-Guryn, K., Huang, Y., Wang, T., Liu, J., He, C., Chang, E. B., \& Leone, V. (2018). Circadian clock regulation of hepatic lipid metabolism by modulation of $\mathrm{m} 6 \mathrm{~A}$ mRNA methylation. Cell Reports, 25, 1816-1828.e4.

Zipeto, M. A., Court, A. C., Sadarangani, A., Delos Santos, N. P., Balaian, L., Chun, H.-J., Pineda, G., Morris, S. R., Mason, C. N., Geron, I., Barrett, C., Goff, D. J., Wall, R., Pellecchia, M., Minden, M., Frazer, K. A., Marra, M. A., Crews, L. A., Jiang, Q., \& Jamieson, C. H. M. (2016). ADAR1 activation drives leukemia stem cell self-renewal by impairing Let-7 biogenesis. Cell Stem Cell, 19, 177-191.

How to cite this article: Berdasco, M., \& Esteller, M. (2021). Towards a druggable epitranscriptome: Compounds that target RNA modifications in cancer. British Journal of Pharmacology, 1-22. https://doi.org/10.1111/bph.15604 